\title{
Identification of Trigeminal Sensory Neuronal Types Innervating Masseter Muscle
}

\author{
Karen A. Lindquist, ${ }^{1}$ Sergei Belugin, ${ }^{2}$ Anahit H. Hovhannisyan, ${ }^{2}$ Tatiana M. Corey, ${ }^{5}$ Adam Salmon, $, 4,6$ \\ and Armen N. Akopian $1,2,3$
}

https://doi.org/10.1523/ENEURO.0176-21.2021

${ }^{1}$ Integrated Biomedical Sciences (IBMS) Program, The University of Texas Health Science Center at San Antonio, San
Antonio, TX 78229, ${ }^{2}$ Endodontics, The University of Texas Health Science Center at San Antonio, San Antonio, TX
$78229,{ }^{3}$ Pharmacology, The University of Texas Health Science Center at San Antonio, San Antonio, TX 78229,
${ }^{4}$ Molecular Medicine, The University of Texas Health Science Center at San Antonio, San Antonio, TX 78229,
${ }^{5}$ Laboratory Animal Resources Departments, The University of Texas Health Science Center at San Antonio, San
Antonio, TX 78229, ${ }^{6}$ Sam and Ann Barshop Institute for Longevity and Aging Studies, The University of Texas Health
Science Center at San Antonio, San Antonio, TX 78229, and ${ }^{7}$ South Texas Veterans Health Care System, Geriatric
Research Education and Clinical Center San Antonio, TX 78229

\begin{abstract}
Understanding masseter muscle (MM) innervation is critical for the study of cell-specific mechanisms of pain induced by temporomandibular disorder (TMDs) or after facial surgery. Here, we identified trigeminal (TG) sensory neuronal subtypes (MM TG neurons) innervating MM fibers, masseteric fascia, tendons, and adjusted tissues. A combination of patch clamp electrophysiology and immunohistochemistry (IHC) on TG neurons back-traced from reporter mouse MM found nine distinct subtypes of MM TG neurons. Of these neurons, $24 \%$ belonged to non-peptidergic IB- $4^{+} / \mathrm{TRPA} 1^{-}$or IB- $4^{+} / \mathrm{TRPA} 1^{+}$groups, while two $\mathrm{TRPV} 1^{+}$small-sized neuronal groups were classified as peptidergic/CGRP ${ }^{+}$. One small-sized $\mathrm{CGRP}^{+}$neuronal group had a unique electrophysiological profile and were recorded from Nav1.8 $8^{-}$or $\mathrm{trkC}^{+}$neurons. The remaining $\mathrm{CGRP}^{+}$neurons

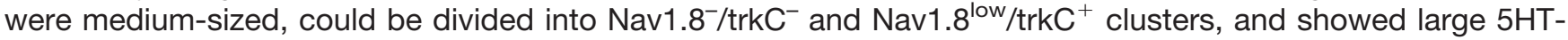
induced current. The final two MM TG neuronal groups were trkC ${ }^{+}$and had no Nav1.8 and CGRP. Among MM TG neurons, TRPV ${ }^{+} / \mathrm{CGRP}^{-}$(somatostatin $^{+}$), tyrosine hydroxylase $(\mathrm{TH})^{+}(\mathrm{C}-\mathrm{LTMR}), \mathrm{TRPM}^{+}, \mathrm{MrgprA3}^{+}$, or $\operatorname{trkB}^{+}(\mathrm{A} \delta$-LTMR) subtypes have not been detected. Masseteric muscle fibers, tendons and masseteric fascia in mice and the common marmoset, a new world monkey, were exclusively innervated by either $\mathrm{CGRP}^{+} /$ $\mathrm{NFH}^{+}$or $\mathrm{CGRP}^{-} / \mathrm{NFH}^{+}$medium-to-large neurons, which we found using a Nav1.8-YFP reporter, and labeling with CGRP, TRPV1, neurofilament heavy chain (NFH) and pgp9.5 antibodies. These nerves were mainly distributed in tendon and at junctions of deep-middle-superficial parts of MM. Overall, the data presented here
\end{abstract}

\section{Significance Statement}

Identification of sensory neuron subtypes innervating masseter muscle (MM) will enable the study of cellspecific mechanisms of masticatory myofascial pain, including temporomandibular disorder (TMD) and after restorative surgeries involving MM. Combining back tracing from MM, patch-clamp electrophysiology, and immunohistochemistry $(\mathrm{IHC})$ with sensory neuronal markers on mouse and nonhuman primate tissues, we identified trigeminal (TG) neuronal groups innervating MM (MM TG neurons). MM and adjacent tissues are innervated by 9 distinct types of TG neurons, some of which are substantially different from L3-L5 DRG neurons. However, MM fibers, tendon, muscle-tendon junction, and fascia in mice and common marmosets are exclusively innervated by medium-to-large neurons. These neurofilament heavy chain (NFH)-positive sensory nerve fibers are mainly distributed in tendon and at junctions between deep, middle, and superficial parts of MM. 
demonstrates that $\mathrm{MM}$ is innervated by a distinct subset of $\mathrm{TG}$ neurons, which have unique characteristics and innervation patterns.

Key words: masseter muscle; myogenous temporomandibular disorders; orofacial pain; sensory neurons; trigeminal

\section{Introduction}

Myofascial pain is widely prevalent in the general population (Cimmino et al., 2011). Pain related to mastication muscles, which are comprised of the temporalis, medial pterygoid, lateral pterygoid, and masseter muscle (MM), is referred to as masticatory myofascial pain. Masticatory myofascial pain may manifest as facial pain, headache, soreness, and fatigue of the masticatory muscles (Gerwin, 2001). This pain type is detected among patients with temporomandibular disorders (TMDs; Lobbezoo et al., 1996; Slade et al., 2016), myofascial pain syndrome (Desai et al., 2013; Galasso et al., 2020), and after craniofacial surgeries done to repair facial paralysis, facelift procedures, or tissue trauma affecting MM (Wieckiewicz et al., 2015; Lassus et al., 2018).

MM consists of three heads (superficial, middle, and deep) of muscle fibers, masseteric fascia, and tendons; and is innervated by the masseteric nerve, a branch of the anterior portion of the mandibular division (V3) of the trigeminal (TG) nerve (Fig. 13A,B). Anatomical studies have revealed myofascial trigger points, which represent tender muscle areas that can elicit pain whenever stimulated during normal or pathologic condition. These myofascial trigger points coincide with neuromuscular junctions at the innervation zone between MM heads (Procopio Pinheiro et al., 2020). Previous observations of the head and neck area showed the presence of nociceptive unmyelinated C- and myelinated A $\delta$ fibers (Strassman et al., 1996; Strassman and Raymond, 1999), as well as low-threshold

Received April 21, 2021; accepted September 1, 2021; First published September 27, 2021.

The authors declare no competing financial interests.

Author contributions: A.S. and A.N.A. designed research; K.A.L., S.B., A.H.H., and T.M.C. performed research; K.A.L., S.B., A.S., and A.N.A. analyzed data; K.A.L. and A.N.A. wrote the paper.

This work was supported by National Institutes of Health/National Institute of Dental and Craniofacial Research Grants DE029187 and DE029187-01S1 (to A.N.A.) and DE029187-01S2 (to K.A.L. and A.N.A.).

Acknowledgements: We thank Richard Lankes (The University of Texas Health Science Center at San Antonio Creative and Brand Department) for preparing cartoons in Figure 13 and Dr. Michael Henry (University of Colorado Anschutz Medical Campus, Aurora, CO) for guidance on IHC. We also thank Dr. Pao-Tien Chuang (University of California San Francisco, San Francisco,

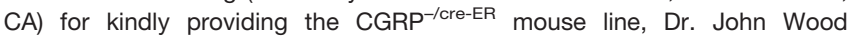
(University College London, London, United Kingdom) for kindly providing Nav1.8 $8^{\text {cre/- }}$ mouse line, and Dr. Yu Shin Kim (The University of Texas Health Science Center at San Antonio) for kindly providing trkC $\mathrm{C}^{-/ \mathrm{cre}-\mathrm{ER}}$ mouse line generated in Dr. David Ginty's laboratory (Harvard Medical School, Boston, MA).

Correspondence should be addressed to Armen N. Akopian at akopian@ uthscsa.edu.

https://doi.org/10.1523/ENEURO.0176-21.2021

Copyright @ 2021 Lindquist et al.

This is an open-access article distributed under the terms of the Creative Commons Attribution 4.0 International license, which permits unrestricted use, distribution and reproduction in any medium provided that the original work is properly attributed. mechanoreceptors (LTMRs) consisting of myelinated $\mathrm{A} \alpha$ and $A \beta$ fibers (Lobbezoo et al., 2002). Similarly, it has been shown that MM has C-fibers, two types of A- $\delta$ highthreshold mechanoreceptors (A $\delta$-HTMR) as well as $\mathrm{A} \beta$ LTMR fibers (Nishimori et al., 1986; Cruccu et al., 1989; Connor et al., 2005; Wong et al., 2014; Sato et al., 2018). $\mathrm{MM}$ is predominantly innervated by $\mathrm{A} \delta-\mathrm{HTMR}$, with cell bodies observed to be $27 \%$ small, $49 \%$ medium, and $24 \%$ large-sized neurons (Sato et al., 2018). However, the precise composition of MM innervating TG ganglion neuronal groups or their properties is unknown.

The understanding of molecular mechanisms governing masticatory myofascial pain is hindered by the limited information on the neuronal circuits undergoing plasticity during TMD and after surgical procedures involving MM and/or masseteric nerve. The aim of the present study has been to identify and comprehensively characterize TG sensory neuronal groups innervating MM (MM TG neurons), and to examine the innervation patterns of $\mathrm{MM}$ by afferent sensory fibers. To do so, back-tracing of sensory neurons from $\mathrm{MM}$, patch-clamp electrophysiology, $\mathrm{Ca}$ imaging, anatomic studies, sensory neuronal reporter mice and tissues from a nonhuman primate species (common marmosets) have been used (Herrity et al., 2014; Patil et al., 2018).

\section{Materials and Methods}

\section{Animals}

All animal experiments conformed to American Pain Society (APS)'s Guiding Principles in the Care and Use of Vertebrate Animals in Research and Training. We also followed guidelines issued by the National Institutes of Health $(\mathrm{NIH})$ and the Society for Neuroscience (SfN) to minimize the numbers of animals used and their suffering. Protocols used in this study (20190114AR for mice and 20200021 AR for nonhuman primates) are approved by the Institution Animal Care and Use Committee (IACUC).

Experiments were performed on 10- to 18-week-old male mice. B6.Cg-Gt(ROSA)26Sortm9(CAG-tdTomato) Hze/J (Ai9; tdTomato; stock 007909), B6.Cg-Gt(ROSA) 26Sortm32(CAG-COP4* H134R/EYFP)Hze/J (Ai32; stock 024109), B6;129P2-Pvalbtm1(cre)Arbr/J (PV-cre; stock

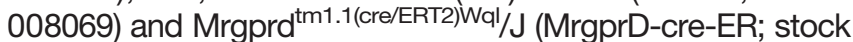
031286) mouse lines were obtained from The Jackson Laboratory. 5HT3a-GFP (also known as Htr3a-EGFP) and TRPV1-GFP transgenic mouse lines were purchased from the GENSAT program (MMRRC services; UNC, NC and UC Davis, CA, respectively). The CGRP ${ }^{\text {cre/+-ER }}$ mouse line was kindly provided by Pao-Tien Chuang (University of California San Francisco, San Francisco, CA). Nav1.8 ${ }^{\text {cre/+ }}$ mouse line was kindly provided by John Wood (University College London, London, United Kingdom). The trkC ${ }^{\text {cre/+-ER mouse }}$ line was generated in David Ginty's laboratory (Harvard 

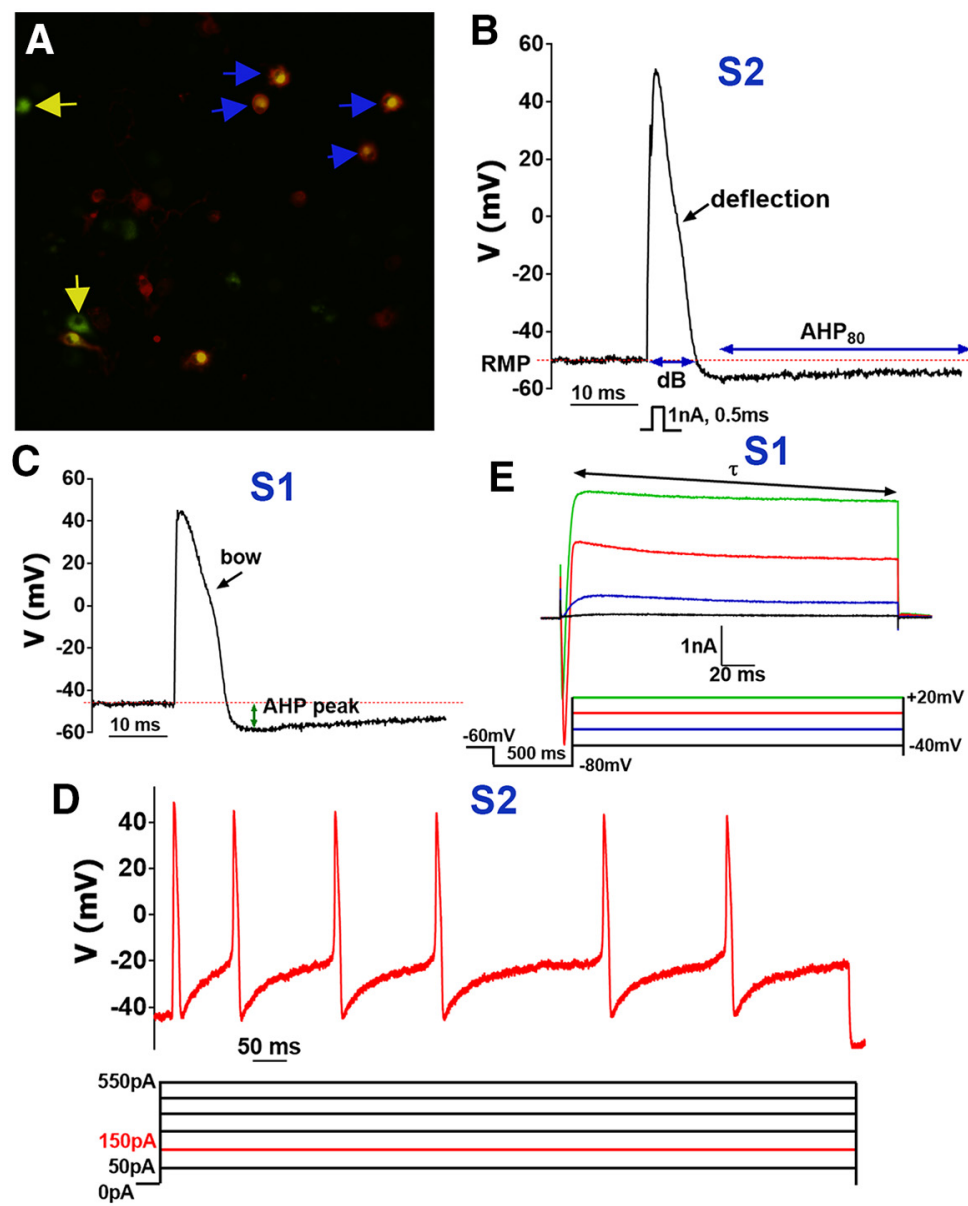

Figure 1. Recordings from non-peptidergic IB4 ${ }^{+} \mathrm{MM}$ TG neurons. $\boldsymbol{A}$, WGA $-488^{+} / \mathrm{IB} 4-555^{+}$(marked with blue arrows), but not WGA- $488^{+} / \mathrm{IB}^{-}$(marked with yellow arrows) were selected for recording non-peptidergic TG neurons innervating MM. $\boldsymbol{B}$, Stimulus waveform (1 nA, $0.5 \mathrm{~ms}$ ) indicated below trace generated a single AP in a WGA ${ }^{+} / \mathrm{IB} 4^{+} \mathrm{TG}$ neuron belonging to the S2 group (Table 1). AP width is duration at base, dB. AHP80 is the time required for the AHP (measured in $m V$ ) to decay by $80 \%$ to a RMP level. Characteristic AP deflection is indicated by black arrow. $\boldsymbol{C}, \mathrm{AP}$ from a WGA ${ }^{+} / \mathrm{IB} 4^{+}$TG neuron belonging to the group S1 (Table 1 ). Distinctive AP feature, bow, is indicated by black arrow. Distance from RMP to a lowest point of AP, AHP peak, is measured as indicated with the green arrow. $\boldsymbol{D}$, Current-evoked AP train from a WGA WB $^{+}{ }^{+}$TG neuron belonging to the S2 group. Current waveforms are below trace and are applied by steps from 50 to $550 \mathrm{pA}$ with 100-pA increment. Depictured AP train is evoked by a $150-$ $\mathrm{pA}$ step lasting $1 \mathrm{~s}$. $\boldsymbol{E}$, Currents were generated from a WGA ${ }^{+} / \mathrm{IB}^{+}{ }^{+} \mathrm{TG}$ neurons belonging to the $\mathrm{S} 1$ group by the indicated waveforms found below traces. The decay constant $\tau$ was derived from standard single exponential fits between points indicated by arrows for the outward portion of the final current trace $(+20 \mathrm{mV})$.

Medical School, Boston, MA) and kindly provided by Yu Shin Kim (The University of Texas Health Science Center at San Antonio). In inducible cre-carrying mouse lines, cre-recombinase was induced in six- to eight-week-old mice by three consecutives (every second day) intraperitoneal injections of $100 \mathrm{mg} / \mathrm{kg}$ tamoxifen (dissolved in corn oil). Cre-recombination occurs within two to three weeks after tamoxifen injection.

Two aged (11- and 15-year-old) male common marmosets (Callithrix jacchus) were used for collection of MM. IACUC and veterinary oversight regularly monitored marmoset housing and animal conditions to ensure all guidelines for the health and safety of the animals were met and research was conducted in compliance with the United States Public Health Service's Policy on Humane Care and Use of Laboratory Animals and the Guide for the Care and Use of Laboratory Animals and adhered to the
American Society of Primatologists (ASP) principles for the ethical treatment of non-human primates. Marmosets were euthanized for humane reasons following veterinary consult and tissue samples were collected immediately following determination of death.

\section{Primary TG neuronal culture}

To visualize MM TG neurons, wild-type or reporter mice expressing GFP, YFP (Ai32), or tdTomato (Ai9) gene were injected into the right and left $\mathrm{MM}$ closer to tendon with $10 \mu \mathrm{l}$ of WGA-488 or WGA-555 (50 $\mu \mathrm{g}$ in $0.5 \%$ DMSO) back-tracer. Neuronal culture for electrophysiology recordings was always generated from one mouse. TG was dissected 24-36 h post-WGA injections, and sensory neurons were cultured as previously described (Belugin et al., 2013). Cells were maintained in DMEM with $2 \%$ fetal 
bovine serum, $2 \mathrm{~mm}$ L-glutamine, $100 \mathrm{U} / \mathrm{ml}$ penicillin, and $100 \mu \mathrm{g} / \mathrm{ml}$ streptomycin. No growth factor was added to the media. The experiments were performed within $24 \mathrm{~h}$ after TG neuron plating. This culture conditions minimize changes in sensory neurons (Patil et al., 2018).

\section{Electrophysiology: recording}

Before patch clamp recording, cultured TG cells from WGA-488-injected wild-type mice were stained for 0.5-4 h with IB-4 Alexa Fluor 594 (1:1000; Thermo-Fisher Scientific). WGA ${ }^{+} / \mathrm{IB}^{-} 4^{+}$TG neurons were selected for recording (Fig. $1 A$ ). Along with $\mathrm{WGA}^{+} / \mathrm{IB}-4^{+} \mathrm{TG}$ neurons

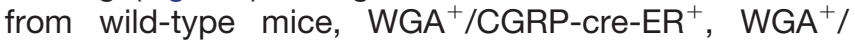
TRPV1-GFP ${ }^{+}, \quad$ WGA $^{+} / 5 \mathrm{HT}^{2} \mathrm{a}-\mathrm{GFP}^{+}, \quad \mathrm{WGA}^{+} / \mathrm{PV}^{-\mathrm{Cre}^{+}}{ }^{+}$, $\mathrm{WGA}^{+} /$trkC-cre-ER ${ }^{+}, \mathrm{WGA}^{+} / \mathrm{Nav} 1.8-\mathrm{Cre}^{+}$, and $\mathrm{WGA}^{+}$/ Nav1.8-cre ${ }^{-}$MM TG neurons were selected for recordings. Overall, we have chosen reporters that are not affected by early developmental changes (Patil et al., 2018).

Recordings were made in patch clamp whole-cell voltage [holding potential $\left(\mathrm{V}_{\mathrm{h}}\right)$ of $-60 \mathrm{mV}$ ] or current clamp configurations at room temperature. Data were acquired using an Axopatch 200B amplifier and analyzed with pCLAMP10.6 software (Molecular Devices). Recording data were filtered at $0.5-5 \mathrm{kHz}$ and sampled at $2-20 \mathrm{kHz}$ depending on current kinetics. Borosilicate pipettes (Sutter) were polished to resistances of $<5 \mathrm{M} \Omega$. If required, access resistance $\left(R_{S}\right)$ was compensated (40$80 \%$ ) to the value of $<6-8 \mathrm{M} \Omega$. Data were rejected when $\mathrm{R}_{\mathrm{S}}$ changed $>20 \%$ during recording, leak currents were $>100 \mathrm{pA}$, or input resistance was $<300 \mathrm{M} \Omega$. Liquid junction potential (LJP) was not corrected using the $V_{\text {meter }}$ $=V_{\text {cell }}+$ LJP equation, since large anions were not included in extracellular or pipette recording solutions. Recordings were made 3-4 min after establishing wholecell configuration to allow for equilibrium. Currents were considered positive when their amplitudes were fivefold bigger than displayed noise (in root mean square).

Standard external solution (SES) contained the following: $140 \mathrm{~mm} \mathrm{NaCl}, 5 \mathrm{~mm} \mathrm{KCl}, 2 \mathrm{~mm} \mathrm{CaCl}, 1 \mathrm{~mm} \mathrm{MgCl}_{2}, 10$ mm D-glucose, and $10 \mathrm{~mm}$ HEPES, pH 7.4. The standard pipette solution (SIS) contained the following: $140 \mathrm{~mm}$ $\mathrm{KCl}, 1 \mathrm{~mm} \mathrm{MgCl} 2,1 \mathrm{~mm} \mathrm{CaCl} 2,10 \mathrm{~mm}$ EGTA, $10 \mathrm{~mm}$ D-glucose, and $10 \mathrm{~mm}$ HEPES, pH 7.3, 2.5 ATP and 0.2 GTP. Drugs were applied by a fast, pressure-driven and computer controlled four-channel system (ValveLink8; AutoMate Scientific) with quartz application pipettes. Recordings were independently performed by two investigators. Data were accumulated from five to eight independent MM TG neuronal cultures for each mouse line. Six to 15 neurons were recorded from each MM-TG neuronal culture.

\section{Electrophysiology: recording protocols and data analysis}

On the selected for recording MM TG neurons, we used a sequence of protocols after fast and slow capacitance compensations: (1) single action potential (AP) in currentclamp configuration was generated with $1 \mathrm{nA}(2 \mathrm{nA}$ for $>40-p F$ cells) 0.5 -ms current pulse (Fig. 1B,C; Petruska et al., 2000; Patil et al., 2018); (2) AP train was induced by applying step currents of 50-550 pA with 100-pA increment for $1 \mathrm{~s}$ (Fig. 1D) or 200-2000 pA with 300-pA increment for medium-to-large neurons; (3) after current clamp recordings the electronics were switched to voltageclamp configuration $\left(\mathrm{V}_{\mathrm{h}}=-60 \mathrm{mV}\right)$ and ATP $(30 \mu \mathrm{M})$ current was recorded by applying drug for $5 \mathrm{~s}$; (4) after ATPgated current, $5 \mathrm{HT}(30 \mu \mathrm{M})$-gated current was recorded by 5-s-long drug application; (5) the next protocol in a voltage-clamp configuration was a step down from $V_{h}$ to $80 \mathrm{mV}$ kept for $500 \mathrm{~ms}$, and then 200-ms depolarizing command steps $(20 \mathrm{mV})$ were applied from $-40 \mathrm{mV}$ to a final potential of $+20 \mathrm{mV}$ (Fig. 1E; Petruska et al., 2000). Time gap between these successive one to five protocols was 1-2 min. In some sets of experiments, mustard oil (MO; $25 \mu \mathrm{M}$ ) and menthol (Ment; $100 \mu \mathrm{M}$ ) responses in MM TG neurons of reporter mice were evaluated using $\mathrm{Ca}^{2+}$ imaging system as previously described (Salas et al., 2009; Patil et al., 2018).

Data on sensory neuronal marker expression in MM TG neurons, capacitance (in $\mathrm{pF}$ ) and resting membrane potential (RMP; $V_{m}$ in $\mathrm{mV}$ ) values were collected prior recording and after application of protocol-1 (Fig. 1A,B). Cells were considered as a spherical, and therefore, diameter (d in $\mu \mathrm{m}$ ) of cells was calculated from capacitance $\left(\mathrm{C}_{\mathrm{m}}\right.$ in $\left.\mathrm{pF}\right)$ values using the following:

$$
\mathrm{d}=5 * \sqrt{ }(\mathrm{Cm} / 4 \pi) .
$$

AP duration at the base $\left(\mathrm{dB}\right.$; time from $\mathrm{V}_{\mathrm{m}}$ starting point to $V_{m}$ levels at falling phase of $A P$ ), after-hyperpolarization (AHP) peak as a distance from RMP to a lowest point of $\mathrm{AP}$ and $80 \%$ recovery time of $\mathrm{AHP}$ to baseline $\left(\mathrm{AHP}_{80}\right)$ were measured from data generated by protocol-1 (Fig. 1B,C; Table 1). Besides these AP parameters, we noted characteristic features of AP shapes, such as "hump," "bow," "deflection," and "straight," on the falling phase of AP (Patil et al., 2018; Figs. 1B,C, 2A,B, 3B,C; Table 1). Analysis of protocol-2 gave AP activation threshold (in $\mathrm{pA}$ ) and maximum AP frequency at the given current input (Fig. 1D; Table 1). Protocol-3 and protocol-4 revealed algesic responses to ATP and $5 \mathrm{HT}$ as well as $I_{\text {ATP }}$ and $I_{5 \mathrm{HT}}$ characteristics (Fig. 3D; Table 1). From protocol-5, the trace evoked by $+20 \mathrm{mV}$ was fit with a standard (i.e., single or double) exponential function using the following:

$$
\mathrm{A} 1 \exp [-(\mathrm{t}-\mathrm{k}) /]+\mathrm{C} .
$$

Fitting and decay tau $(\tau ; \mathrm{ms})$ calculation was performed using pCLAMP10.6 software (Fig. 1E). Shape of current (I), including presence or absence of "spike-like" feature at steps to 0 and $+20 \mathrm{mV}$, was an important clustering variable (Figs. $3 F, 4 C$ ). Clustering is based on at least two unique features for a specified cluster (Table 2). An approach for generation of clustering parameters described in detail in Results and in the previous publication (Patil et al., 2018).

\section{Immunohistochemistry (IHC)}

Wild-type male C57/BI mice were injected into the right and left MM close to the tendon with $10 \mu \mathrm{l}$ of WGA-488 
Table 1: Properties of MM TG neuronal groups

\begin{tabular}{|c|c|c|c|c|c|c|c|c|c|c|c|c|c|c|}
\hline $\mathrm{Gr}^{1}$ & Marker & $N$ & Size; $\mu \mathrm{m}^{2}$ & RMP; mV & $\mathrm{dB} ; \mathrm{ms}$ & Shape $^{3}$ & $\mathrm{AHP}_{80} ; \mathrm{ms}$ & AHP peak ${ }^{4}$ & AP Thr.; pA & AP train; $\mathrm{Hz}$ & ATP & $5 \mathrm{HT} ; \mathrm{pA}$ & Tau; ms & Shape Curr ${ }^{5}$ \\
\hline \multirow[t]{2}{*}{$\mathrm{S} 1$} & IB4 & 16 & $20.5 \pm 0.8$ & $-40.4 \pm 2.1$ & $11.9 \pm 1.1$ & Bow & $35.2 \pm 4.9$ & $-14.5 \pm 1.2$ & $405 \pm 177$ & $10 \pm 2.2$ & 0 & 0 & $19.2 \pm 6.5$ & Smooth \\
\hline & Nav1.8 & & & & & & & & & & & & & \\
\hline \multirow[t]{2}{*}{ S2 } & IB4 & 52 & $19.9 \pm 0.4$ & $-41.3 \pm 1.0$ & $11.5 \pm 0.6$ & Deflection & $67.9 \pm 4.0$ & $-19.0 \pm 0.8$ & $156.6 \pm 20.3$ & $8.3 \pm 0.8$ & 0 & 0 & $26.3 \pm 4.2$ & Smooth 6,7 \\
\hline & Nav1.8 & & & & & & & & & & & & & \\
\hline \multirow[t]{3}{*}{ S3 } & trpV1 & 47 & $21.4 \pm 0.4$ & $-44.7 \pm 1.0$ & $8.7 \pm 0.3$ & Hump & $76.3 \pm 17.2$ & $-13.7 \pm 0.9$ & $109.1 \pm 23.4$ & $11.8 \pm 2.2$ & 0 & 0 & $20.6 \pm 2.6$ & Smooth ${ }^{7}$ \\
\hline & CGRP & & & & & & & & & & & & & \\
\hline & Nav1.8 & & & & & & & & & & & & & \\
\hline \multirow[t]{3}{*}{ S4 } & $\operatorname{trpV} 1$ & 24 & $21.4 \pm 0.9$ & $-43.0 \pm 1.1$ & $8.5 \pm 0.5$ & Deflection & $63.5 \pm 20.5$ & $-10.3 \pm 1.4$ & $64.3 \pm 14.3$ & $6.3 \pm 1.3$ & 0 & 0 & $16.9 \pm 2.1$ & Smooth $^{6}$ \\
\hline & CGRP & & & & & & & & & & & & & \\
\hline & Nav1.8 & & & & & & & & & & & & & \\
\hline \multirow[t]{3}{*}{ S5 } & CGRP & 30 & $21.5 \pm 1.0$ & $-44.7 \pm 1.5$ & $7.7 \pm 0.5$ & Straight & $65.2 \pm 16.7$ & $-13.7 \pm 1.3$ & $50.0 \pm 0$ & $22 \pm 3.8$ & 0 & $195 \pm 18$ & $24 \pm 4.6$ & Box like 6 \\
\hline & $5 \mathrm{HT} 3 \mathrm{a}$ & & & & & & & & & & & & & \\
\hline & trkC & & & & & & & & & & & & & \\
\hline \multirow[t]{2}{*}{ M1 } & CGRP & 34 & $29.5 \pm 0.9$ & $-52.1 \pm 1.1$ & $6.3 \pm 0.2$ & Deflection & $92.4 \pm 11.7$ & $-13.2 \pm 1.2$ & $316 \pm 107$ & $10 \pm 3.7$ & 0 & $818 \pm 100$ & $3.5 \pm 0.6$ & Box like $^{6}$ \\
\hline & $5 \mathrm{HT3a}$ & & & & & & & & & & & & & \\
\hline \multirow[t]{4}{*}{$\mathrm{M} 2^{9}$} & CGRP & 66 & $30.7 \pm 0.5$ & $-51.6 \pm 1.6$ & $4.8 \pm 0.2$ & Straight & $73.6 \pm 9.1$ & $-13.3 \pm 0.5$ & $580 \pm 128$ & $13.1 \pm 3.3$ & 0 & $774 \pm 88$ & $22.0 \pm 2.3$ & Spike \\
\hline & $5 \mathrm{HT} \mathrm{a}^{8}$ & & & & & & & & & & & & & \\
\hline & trkC & & & & & & & & & & & & & \\
\hline & PV & & & & & & & & & & & & & \\
\hline \multirow[t]{2}{*}{ M3 } & trkC & 56 & $33.5 \pm 0.6$ & $-55.2 \pm 0.6$ & $2.8 \pm 0.1$ & Straight & $86.3 \pm 12.0$ & $-10.3 \pm 0.6$ & $1280 \pm 152$ & $7 \pm 2.3$ & 0 & $0^{11}$ & $22.3 \pm 1.9$ & Spike ${ }^{10}$ \\
\hline & PV & & & & & & & & & & & & & \\
\hline \multirow[t]{2}{*}{ M4 } & trkC & 40 & $30.5 \pm 0.8$ & $-54.0 \pm 0.7$ & $1.9 \pm 0.06$ & Straight & $6.9 \pm 0.6$ & $-10.7 \pm 0.8$ & 0 & 0 & 0 & 0 & $16.0 \pm 2.7$ & Box like \\
\hline & PV & & & & & & & & & & & & & \\
\hline
\end{tabular}

\footnotetext{
${ }^{1}$ Green font is non-peptiderigic; red font is peptidergic, and blue font is mechanoreceptors.

${ }^{2}$ Size in $\mu \mathrm{m}$ is calculated from pF (see Materials and Methods).

${ }^{3}$ Characteristic feature on AP downstroke: bow, hump, deflection, and straight (Figs. 1B, C, 2A)

${ }^{4} \mathrm{AHP}_{80}$ peak is a lowest point of $\mathrm{AP}$, and it is measured in negative $\mathrm{mV}$.

${ }^{5}$ Characteristic feature of the last (generated by stepping to $+20 \mathrm{mV}$ ) outward current: "smooth," "box like," and "spike" (Figs. $\left.1 E, 2 D, E, 3 E, F, 4 C, D\right)$.

${ }^{6}$ Currents do not have inward component.

${ }^{7}$ Neurons are responsive to $\mathrm{MO}$.

${ }^{8} 5 \mathrm{HT} 3 \mathrm{a}$ is encoded by Htr3a gene.

${ }^{9}$ Contain low level Nav1.8.

${ }^{10}$ Spike is sharper in M3 than M2.

${ }^{11}$ Some $(\approx 15 \%) \mathrm{M} 3$ neurons respond to $5 \mathrm{HT}(30 \mu \mathrm{M})$.
}

(50 $\mu \mathrm{g}$ in 0.5\% DMSO) back-tracer. TG was dissected at 2 d post-WGA injection from $4 \%$ paraformaldehyde-perfused mice. MM was dissected from WGA un-injected wild-type mice. TG and MM were collected from two aged marmosets (11 and 15 years of age) that were not injected with WGA. TG and MM from both species were additionally fixed with $4 \%$ paraformaldehyde for $15 \mathrm{~min}$, cryo-protected overnight with $30 \%$ sucrose in phosphate buffer, embedded in Neg 50 (Richard Allan Scientific), and 25$\mu \mathrm{m}$ transverse cryo-sections were generated from both mouse and marmoset TG and MM as previously described (Belugin et al., 2013). IHC was conducted as described (Belugin et al., 2013). IHC was simultaneously performed on 6-12 sections generated from three or four mice; or three to four sections generated from the marmoset tissue. The following previously characterized primary antibodies were used for mouse sections: anti-neurofilament heavy chain (NFH) chicken polyclonal antibodies (BioLegend, catalog \#PCK-592P, 1:400; Zappulo et al., 2017); anti-pgp9.5 (Millipore-Sigma, catalog \#AB1761-I, 1:1000; Roy et al., 2020); anti-TRPV1 guinea pig polyclonal (Neuromics, catalog \#GP14100, 1:700; Patil et al., 2014); anti-CGRP rabbit polyclonal (Sigma, C8198, 1:300; Ruparel et al., 2008; Neeb et al., 2011; Lorenzo et al., 2014); anti-tyrosine hydroxylase (TH) rabbit polyclonal (Pel-Freez, P40101, 1:400; Dunkley et al., 2004; Ma et al., 2004); anti-mrgD rabbit polyclonal (Alamone Lab, AMR-
061, 1:200; Chang et al., 2016; Patil et al., 2018); anti-trkC goat polyclonal (R\&D Systems, AF1404, 1:200; Arcourt et al., 2017; Patil et al., 2018); anti-trkB goat polyclonal (R\&D Systems, AF1494, 1:200; Ninkina et al., 1997; Arcourt et al., 2017); rabbit anti-parvalbumin (Swant, PV25, 1:500; Schurmans et al., 1997; Schwaller et al., 1999; Arcourt et al., 2017); and rabbit anti-Calbindin D28k (Swant, CB38a, 1:500; Schurmans et al., 1997; Arcourt et al., 2017). Antibodies for MrgprD and PV produced weaker signals compare to other antibodies and GFP/YFP/tdTomato signals, hence their intensities were increased, and backgrounds were reduced. Anti-NFH and anti-pgp9.5, but not anti-CGRP produced clear IHC signals in marmoset sections (Resnikoff et al., 2019). Sections were incubated with species appropriate Alexa Fluor secondary antibodies (1:200; Invitrogen).

Images were acquired using a Keyence BZ-X810 Allin-One Fluorescent Microscope (Keyence) or a Nikon Eclipse 90i microscope (Nikon Instruments) equipped with a C1si laser scanning confocal imaging system. Images were processed with NIS-elements (Nikon Instruments) and Adobe Photoshop CC 2019 software. Gain setting was constant during acquisition, and it was established on no primary control slides. Control IHC was performed on tissue sections processed as described but either lacking primary antibodies or lacking primary and secondary antibodies. Cell counts from 

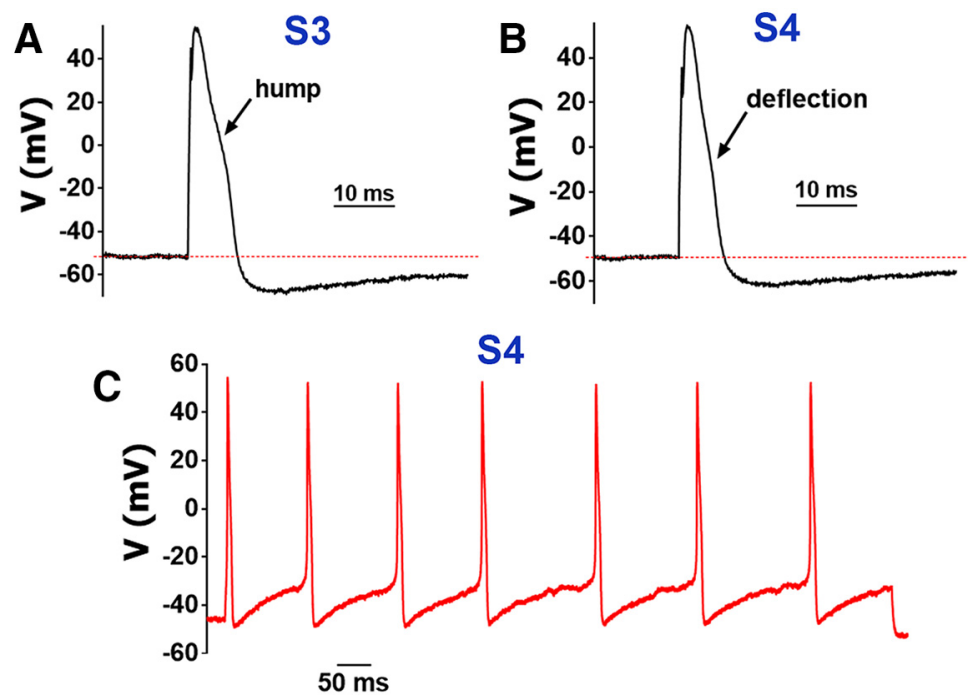

S3

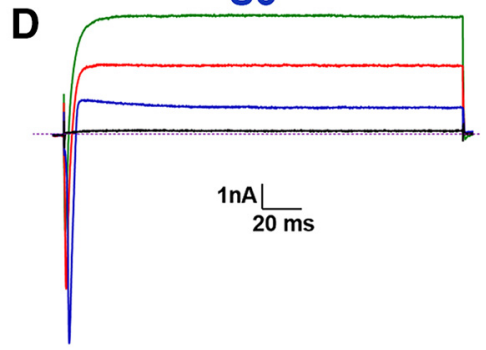

S4

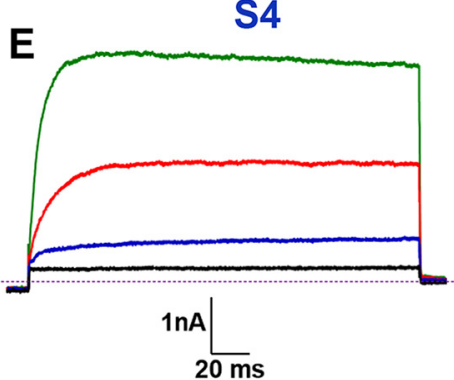

Figure 2. Recordings from TRPV1 ${ }^{+} \mathrm{MM}$ TG neurons. $\boldsymbol{A}$, In MM TG neurons belonging to the group S3, a single $\mathrm{AP}$ in $\mathrm{WGA} \mathrm{T}^{+} / \mathrm{TRPV} 1^{+}$ neuron is generated by current pulse (protocol-1), which has characteristic hump on down stroke phase of AP. $B$, In MM TG neurons belonging to the group S4, a single AP in $\mathrm{WGA}^{+} / \mathrm{TRPV}^{+}{ }^{+}$neuron has distinctive deflection on down stroke phase of AP. $\boldsymbol{C}, \mathrm{Current}-\mathrm{evoked}$ $\mathrm{AP}$ train from a WGA ${ }^{+} / \mathrm{TRPV}^{+}{ }^{+} \mathrm{TG}$ neuron belonging to the group S4. Depictured AP train is evoked by a 50-pA step lasting $1 \mathrm{~s}$. $\boldsymbol{D}$, In $\mathrm{WGA}^{+} / \mathrm{TRPV}^{+}{ }^{+} \mathrm{TG}$ neurons belonging to the group S3, currents were generated by waveforms from Figure $1 E$. E, In WGA ${ }^{+} / \mathrm{TRPV}^{+} \mathrm{TG}^{-}$ neurons belonging to the group $\mathrm{S} 4$, currents generated by waveforms from Figure $1 E$ do not have inward component.

IHC images acquired as Z-stuck were performed using ImageJ software. Cells positive for WGA and each marker as well as the combinations of markers were counted. We used three or four independent mice $(n=3-4)$ to generate sections and counted three to five sections per mouse. Mean values from these three to five sections represented $n$ of 1 .

\section{Statistical analysis}

GraphPad Prism 8.0 (GraphPad) was used for statistical analyses. Data in the figures are mean \pm SEM, with $n$ referring to the number of mice used for IHC and the numbers of analyzed recorded cells. Differences between IHC and electrophysiologically characterized groups were assessed by unpaired $t$ test or regular one-way ANOVA with Tukey's post hoc tests, each column was compared with all other columns. A difference is accepted as statistically significant when $p<0.05$. Interaction $F$ ratios and the associated $p$ values are reported.

\section{Results}

Sensory neurons have previously been identified and classified using multiple methods including, back-tracing from the target tissue (da Silva Serra et al., 2016), sensory neuron reporter mice, patch-clamp recording and classification according to AP properties, sensitivity to algesic agents and appearances of a variety of voltage-gated currents (Xu et al., 2010; Li et al., 2011; Patil et al., 2018) and IHC (Patil et al., 2018). Described in Materials and Methods, back-tracing from MM will label TG neurons innervating $\mathrm{MM}$ fibers, tendon, muscle-tendon junction, and massteric fascia. This approach could have two drawbacks. First, along with these MM structures, diffusion of WGA injected into MM led to labeling of adjusted tissues such as masseteric nerve fibers and the subcutaneous layer of facial skin (Fig. 13A,B). Second, WGA produces nonuniform size-dependent labeling of neurons (Robertson, 1990). This nonuniform labeling of TG neurons is unlikely miss entire neuronal group since there is a variation in neuronal sizes within every TG neuronal group. Patch clamp experiments from these WGA-labeled MM TG neurons will yield data on 12 variables: cell size, RMP, AP width (dB), characteristic features of AP shapes, AHP-peak, $\mathrm{AHP}_{80}$, responsiveness to 5HT, ATP, capsaicin (CAP), MO, and Ment, $\tau$ (tau) from fitting of voltage-gated currents (I), and shape of these I, including presence or absence of a spike-like feature on outward portions of these voltage-gated currents (Table 1). 

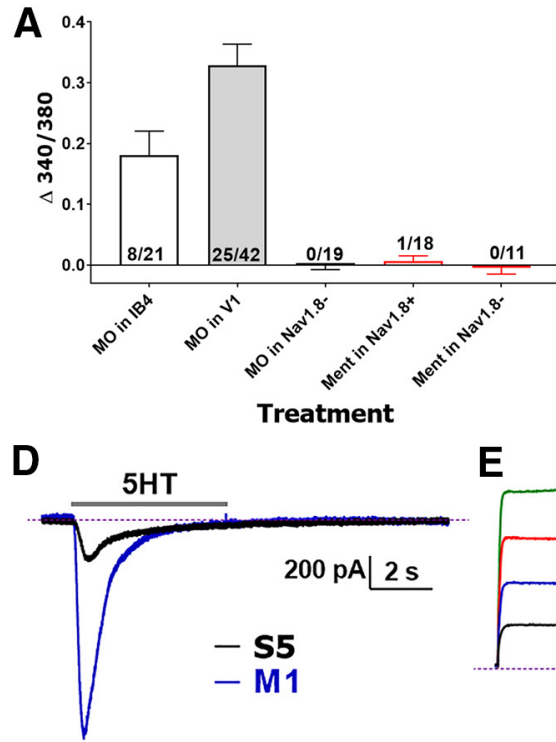
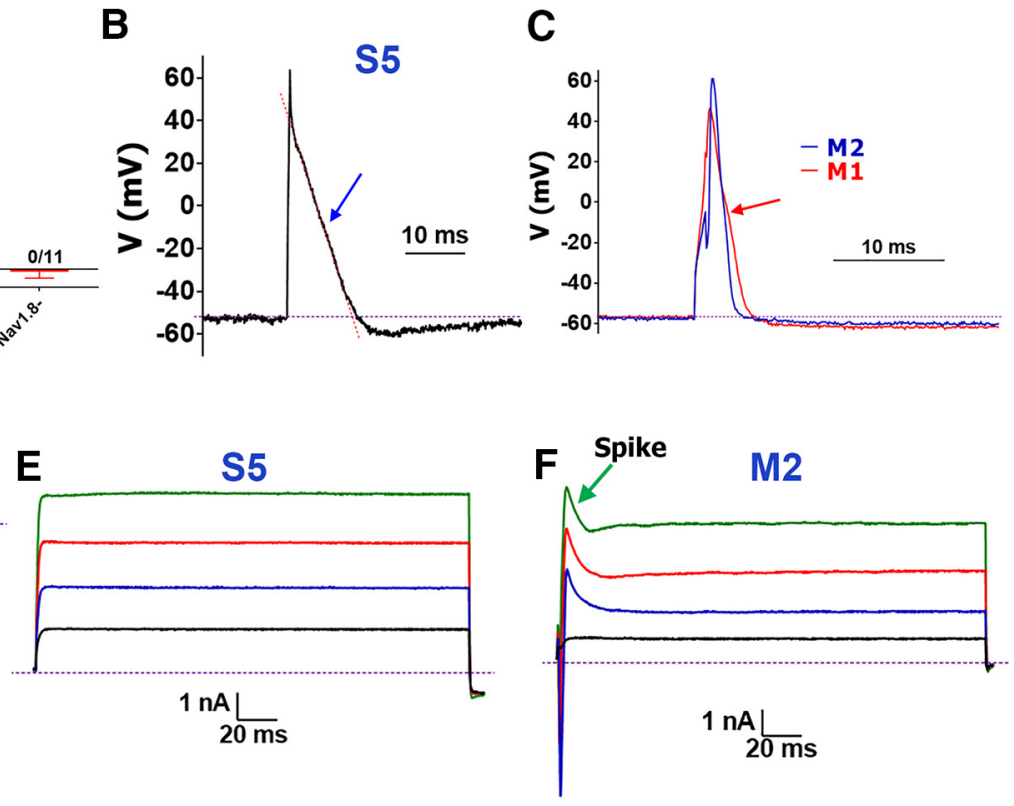

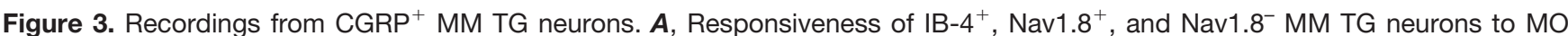
$(25 \mu \mathrm{m})$ and Ment $(100 \mu \mathrm{m})$ measured with $\mathrm{Ca}^{2+}$ imaging. Each bar shows information on numbers of tested and responsive neurons. $\boldsymbol{B}$, Representative AP from a MM TG CGRP ${ }^{+}$neuron belonging to the S5 group. AP straight in S5 neurons is indicated with a blue arrow. Red dashed line demonstrates the AP shape. $\boldsymbol{C}$, Comparison of AP shapes generated in $\mathrm{MM} \mathrm{TG} \mathrm{CGRP}^{+}$neurons belonging to the M1 (red) and M2 (blue) groups. AP deflection in M1 neurons is indicated with a red arrow. M2 neuron's AP does not display any deflection during the falling phase of AP. $\boldsymbol{D}, 5 \mathrm{HT}(30 \mu \mathrm{m})$-induced current in MM TG CGRP ${ }^{+} \mathrm{S} 5$ and M1 group neurons. The drug was applied for $5 \mathrm{~s}$, and duration of application is indicated by a horizontal gray bar. E, Typical current (I) produced from MM TG CGRP ${ }^{+}$neurons belonging to the S5 or M1 group. $\boldsymbol{F}$, Typical I produced from MM TG CGRP ${ }^{+}$M2 group neurons. Characteristic spike is indicated by green arrow. Names of neuronal groups are specified above traces. The magnitude (vertical) and time (horizontal) scale bars are presented for the $\boldsymbol{B}-\boldsymbol{F}$ panels.

\section{IB4 ${ }^{+}$MM TG sensory neuronal groups}

Cultured TG neurons from wild-type male mice backtraced with WGA-488 from MM were stained with IB-4555 for $0.5-4 \mathrm{~h}$ (Patil et al., 2018). WGA ${ }^{+}$cells considered $\mathrm{IB}-4^{+}$, when strong and clear plasma membrane staining was detected (Fang et al., 2006; Fig. 1A). These strongly stained IB- $4^{+}$neurons have been considered as non-peptidergic (Stucky and Lewin, 1999). Seventy-one WGA ${ }^{+}$/ IB-4 ${ }^{+}$MM TG neurons (Fig. 1A) were recorded with sequential protocols as described in the Materials and Methods. All but three IB- $4^{+}$MM TG neurons could be assigned to one of two clusters (S1 and S2; Table 1). S1 and S2 have many similar features such as size, RMP, broad $\mathrm{AP}$ (i.e., high dB values; Fig. $1 B, C$ ), $\mathrm{AHP}_{80}$, time to AHP peak, non-responsiveness to ATP, 5HT and CAP, capability to produce evoked AP train (Fig. 1D) and $\tau$ values (Table 1). S2 IB-4 ${ }^{+}$MM TG neurons are distinct from S1 because of the following three findings: only $\mathrm{S} 2$ neurons were responsive to $\mathrm{MO}$ ( $25 \mu \mathrm{m}$; TRPA1 agonist; Fig. $3 A)$; S2 has deflection on AP (Fig. 1B), while S1 has bow (Fig. 1C); and unlike S1 but like S4, current (I) in S2 neurons had no inward component (compare Figs. $1 E$ and $2 E)$. S1 and S2 are different from other types of MM TG neurons as we observed staining with IB-4, but no $\mathrm{CGRP}^{+}$labeling (i.e., IB- $4^{+} / \mathrm{CGRP}^{-}$neurons). Overall, we observed two subtypes of non-peptidergic smallsized TG neurons labeled after back-tracing with WGA from MM.

\section{TRPV1 ${ }^{+}$MM TG sensory neuronal groups}

Fifty-five TRPV1 ${ }^{+} \mathrm{MM}$ TG neurons $\left(\mathrm{WGA}^{+} / \mathrm{TRPV}^{+}{ }^{+}\right.$) were recorded from TRPV1-GFP reporter mice (Patil et al., 2018). Two groups (S3 and S4) were delineated. S3 and S4 had several common electrophysiological properties: size, RMP, broad AP, AHP 80 , time to AHP peak (Fig. $2 A, B$ ), non-responsiveness to ATP and $5 \mathrm{HT}$, capabilities to produce evoked AP train (Fig. $2 C$ ) and $\tau$ values (Table 1). We found $S 3$ TRPV $1^{+}$MM TG neurons were differentiated from S4 because of the following: only S3 neurons were responsive to $\mathrm{MO}$ (Fig. $3 A$ ); S3 had a hump (more pronounced than deflection) on AP (Fig. $2 A$ ), while S4 had a deflection (Fig. 2B); and unlike S4, current (I) in S3 neurons had a large inward component (compare Fig. 2D,E). S3 and S4 are dissimilar from other types of TG neurons back-traced from MM in expression of TRPV1 and responsiveness to CAP (Table 2). In summary, there are two subtypes of TRPV1 ${ }^{+}$small-sized TG neurons labeled by WGA injected into MM.

\section{CGRP $^{+}$MM TG sensory neuronal groups}

A total of 122 CGRP $^{+}$MM-TG neurons were recorded and analyzed. We selected approximately equal numbers of small-sized $(<30 \mathrm{pF})$ and medium-to-large-sized $(>30$ $\mathrm{pF}$ ) neurons for recording. A majority (48 from 62) of small-sized $(<30 \mathrm{pF}) \mathrm{WGA}^{+} / \mathrm{CGRP}^{+}$neurons were CAP responsive and according to their properties, could be classified as either S3 or S4 (Table 1). This indicated that 

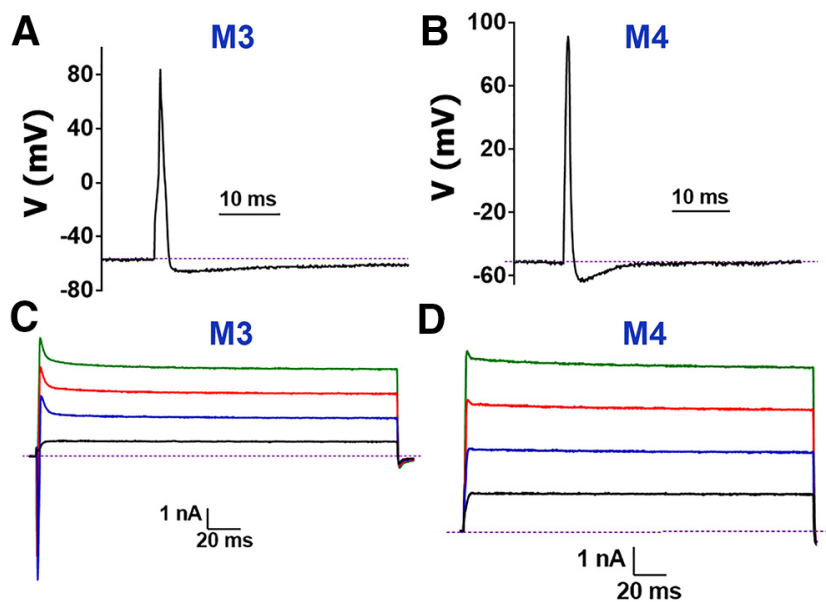

Figure 4. Recordings from Nav1.8 $8^{-}$and trkC ${ }^{+} \mathrm{MM}$ TG neurons. $\boldsymbol{A}$, Representative AP from a MM TG trkC ${ }^{+}$neuron belonging to the M3 group. $\boldsymbol{B}$, Representative AP from a MM TG trkC ${ }^{+}$neuron belonging to the M4 group. $\boldsymbol{C}$, Typical I produced from the M3 group neurons recorded either from a MM TG trkC $^{+}$or Nav1.8 $8^{-}$neuron. Characteristic spike is indicated by green arrow. $\boldsymbol{D}$, Typical I produced from the M3 group neurons recorded from a MM TG trkC ${ }^{+}$or Nav1.8 neuron. Names of neuronal groups are specified above traces on the $\boldsymbol{A}-\boldsymbol{D}$ panels. The magnitude (vertical) and time (horizontal) scale bars are presented for the $\boldsymbol{A}-\boldsymbol{D}$ panels.

all TRPV1 ${ }^{+}$MM TG neurons were peptidergic small-sized neurons. Fourteen small-sized $\mathrm{WGA}^{+} / \mathrm{CGRP}^{+}$neurons, clustered as $\mathrm{S} 5$, had unique characteristics: straight shape on falling phase of AP (Fig. 3B), small 5HT-evoked current (Fig. 3D), no response to CAP, MO, and Ment (TRPM8 agonist), and "box"-shaped current without an inward component (Fig. 3E). Moreover, S5 neurons readily generated an AP train even after 50-pA current injection (Table 1).

Sixty recorded and analyzed medium-to-large-sized CGRP $^{+}$MM TG neurons could be divided into two groups, M1 and M2. Unlike all small-to-large-sized (i.e., S1-S5) and other medium-to-large-sized (i.e., M3 and M4) MM TG neurons, M1 and M2 possessed a large 5HTevoked inward current (Fig. 3D; Table 1). We have additionally recorded from $24 \mathrm{WGA}^{+} / 5 \mathrm{HT}^{3} \mathrm{a}^{+}$neurons cultured from 5HT3a-GFP reporter mouse TG. All recorded neurons were classified as either S5, M1 or M2, and responded to 5HT (Fig. 3D). Unlike small-sized MM TG neurons (S1-S5 groups), large current injections were required to produce AP train, which was detected only in $10-20 \%$ of M1 and M2 neurons (Table 1). The I (current) recorded from M1 was like S5 neurons, having the lowest $\tau$ values among all MM TG neuronal groups (one-way ANOVA; $F_{(8,261)}=5.631 ; p<0.0001$; Fig. $3 E$; Table 1). The most distinct features of M2 compare to M1 neurons was their significantly narrower AP ( $t$ test; $t=5.149 \mathrm{df}=109$; $p<0.0001$; Fig. $3 C$ ) and substantially different shape of current (I) with spike and large inward component (compare Fig. 3E,F). These characteristics indicate that $M 1$ and $\mathrm{M} 2$ belong to medium-sized peptidergic TG MM neurons.

\section{Nav1.8 ${ }^{-}$, trkC ${ }^{+}$, and $\mathrm{PV}^{+}$MM TG sensory neuronal groups}

Eighty-six Nav1.8 ${ }^{-}$MM TG neurons were recorded and analyzed. All 16 small Nav1.8 $8^{-}$MM TG neurons $(<30 \mathrm{pF})$ belonged to the S5 neuronal group. Twenty-six Nav1.8 MM TG neurons were classified as M1 (6 neurons) or M2 (20 neurons). The remaining neurons could fit into two clusters - M3 and M4 (Tables 1, 2). Size, RMP, AHP peak, $\mathrm{AHP}_{80}, \tau$, presence of spike on the I (Figs. 3F, 4C) and requirement of large current to generate AP train were similar for M3 versus M2 neurons (Table 1). An exception was $\mathrm{AP} \mathrm{dB}$, which was significantly narrower for $\mathrm{M} 3$ compared with $\mathrm{M} 2$ neurons ( $t$ test; $t=9.622 \mathrm{df}=125 ; p<0.0001$; Fig. $4 A)$. However, the most critical parameter distinguishing M3 from M2 was their responsiveness to $5 \mathrm{HT}$, which was detected exclusively in M2 neurons (Tables 1, 2). M4 neurons had several unique properties distinguishing them from other MM TG neurons. First, no AP train could be generated even with an injection of 2-nA current (protocol-2). Second, M4 neurons were fastest and had the smallest dB value (one-way ANOVA; $F_{(8,347)}=$ 91.21; $p<0.0001$; Fig. 4B; Table 1). Third, $\mathrm{AHP}_{80}$ was fastest in M4 neurons (one-way ANOVA; $F_{(8,279)}=6.398$; $p<0.0001$; Fig. 4B; Table 1). Fourth, the I from M4 neurons had a "box-like" shape but possessed a small spike (Fig. 4D). We also recorded algesic currents from medium-to-large sized MM TG neurons. These neurons did not have ATP, MO, and Ment-gated currents (Fig. $3 A$; Table 1).

Next, using reporter mice, we recorded and analyzed $65 \mathrm{trkC}^{+}, 32 \mathrm{PV}^{+}$, and 35 medium-to-large sized Nav1.8 ${ }^{+}$ MM TG neurons. This information revealed that trkC was expressed by S5, M2-M4 neurons; PV was present in M2-M4 groups; and Nav1.8 was mainly detected in S1-

Table 2: Clustering parameters for MM TG neuronal groups

\begin{tabular}{|c|c|c|}
\hline $\mathrm{Gr}$ & Key clustering parameters & Putative function \\
\hline$\overline{\mathrm{S} 1}$ & $\mathrm{IB}^{+}{ }^{+} \mathrm{CGRP}^{-}$; non-responsive to $\mathrm{MO}$ and $\mathrm{CAP}$ & Non-peptidergic; C-nociceptor \\
\hline S3 & $\mathrm{TRPV}^{+} / \mathrm{CGRP}^{+} ; \mathrm{AP}$ hump & Peptidergic; C-nociceptor \\
\hline S5 & $\mathrm{CGRP}^{+} / 5 \mathrm{HT} \mathrm{a}^{+} / \mathrm{Nav} 1.8^{-}$; AP straight; box-like current; small response to $5 \mathrm{HT}$ & ? \\
\hline M1 & $\mathrm{CGRP}^{+} / \mathrm{Nav}_{1.8^{+}}$; AP deflection; box-like current; big response to $5 \mathrm{HT}$ & A $\delta$-nociceptors \\
\hline M2 & 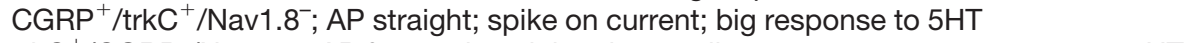 & $?$ \\
\hline
\end{tabular}



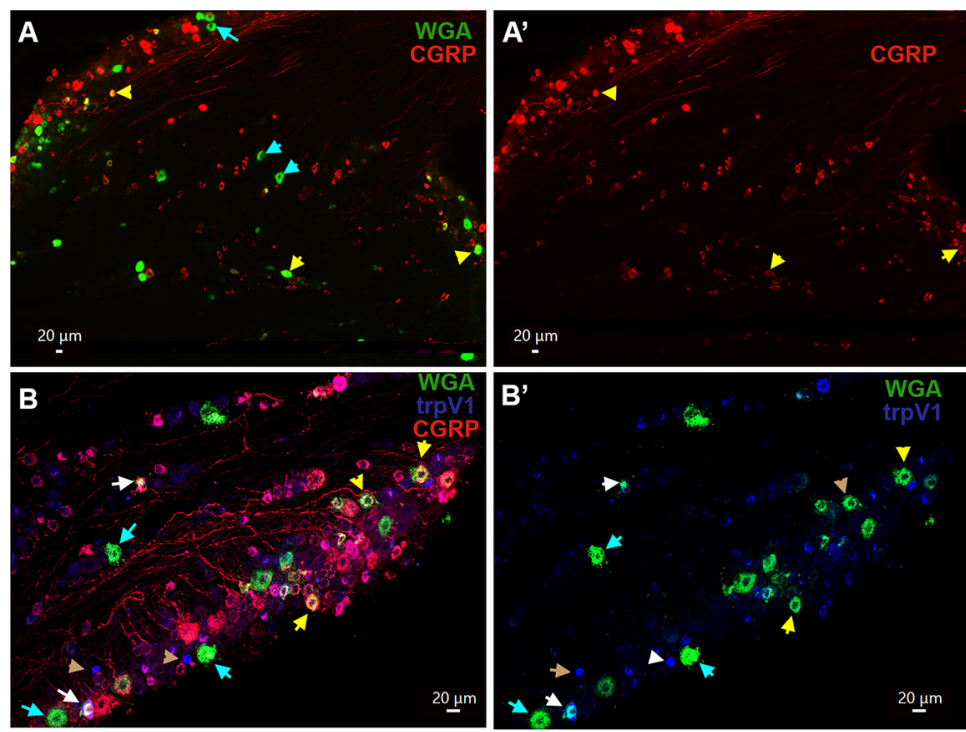

Figure 5. Expression of CGRP and TRPV1 in MM TG neurons. $\boldsymbol{A}, \boldsymbol{A}^{\prime}$, Expression of CGRP (red) neurons in a TG section containing MM TG neurons (WGA; green). Objective is $10 \times . \boldsymbol{B}, \boldsymbol{B}$ ', Expression of CGRP (red) and trpV1 (blue) neurons in a TG section containing MM TG neurons (WGA; green). Objective is $20 \times$. MM TG neurons lacking marker are marked with cyan arrows on the $\boldsymbol{A}-\boldsymbol{C}$ panels. MM TG neurons containing both WGA and CGRP or trpV1 are marked with yellow arrows. MM TG neurons containing WGA, but not CGRP or trpV1, are marked with cyan arrows. MM TG neurons containing both CGRP and trpV1 are marked with white arrows on the $\boldsymbol{B}, \boldsymbol{B}^{\prime}$ panels. TrpV1 neurons lacking CGRP and WGA are marked with brown arrows on the $\boldsymbol{B}, \boldsymbol{B}^{\prime}$ panels. White horizontal bar shows $20-\mu \mathrm{m}$ scale for each panel.

S4 groups. Medium-to-large sized Nav1.8 $8^{+}$MM TG neurons had weaker YFP signal than Nav1.8 $8^{+}$small-sized neurons. A bulk majority of medium-to-large sized Nav1. $8^{+}$MM TG neurons belonged to the M1 group, but four of 35 were classified into the M2 group. Since M1 and M2 neurons were recorded among Nav1.8 $8^{+}$and Nav1.8 $8^{-}$neurons, this suggests that they had weak Nav1.8 expression, which was sufficient to drive Ai32 reporter in some, but not for all M1 and M2 neurons.

Figure $13 \mathrm{C}$ summarizes clustering of TG neurons labeled by back-tracing from MM. These clusters were generated on this basis of electrophysiological properties obtained from recordings on TG neurons isolated from different reporter mouse lines. Unlike previously characterized L3-L5 DRG neurons, which innervate the skin and muscle of legs, TG neurons labeled by backtracing from MM did not have small-sized TRPV $1^{+}$/ CGRP $^{-}$(somatostatin $^{+}$) neurons (Usoskin et al., 2015; Sharma et al., 2020), TRPM $^{+}$(cold thermoceptors) neurons (Sharma et al., 2020) and strongly responding to ATP $\mathrm{MrgprA3}^{+}$neurons (Usoskin et al., 2015; Patil et al., 2018). MM TG neurons also did not have multiple small-sized peptidergic groups (Patil et al., 2018; Zeisel et al., 2018). Expectedly, MM TG lacked neuronal groups associated with innervation of hairs: C-LTMR and A $\delta$-LTMR, which are Nav1.8 ${ }^{+} /$CGRP $^{-} /$trkC $^{-}$(Usoskin et al., 2015) and have distinct AP (Patil et al., 2018). Finally, MM TG neurons do not have proprioceptors (Sharma et al., 2020), which are located in a brain stem region of the TG system. Overall, MM TG neuronal groups were found to be substantially different from the well-characterized L3-L5 DRG neuronal clusters, and S5 and M2 groups have no analogs among L3-L5 DRG neurons (see Discussion).

\section{IHC analysis of MM TG sensory neuronal groups}

To further characterize the MM TG sensory neuronal groups and confirm our electrophysiology data, we used IHC to examine expression of sensory neuronal markers in TG neuron sections from naive male mice injected with WGA-488 into MM. Peptidergic MM TG neurons (S3-S5, M1, and M2 groups) labeled with CGRP antibodies composed $51.7 \pm 2.1 \%$ of $\mathrm{WGA}^{+} \mathrm{TG}$ neurons (Figs. $5 A, A^{\prime}$, $8 C)$. Modest $15.3 \pm 2.4 \%$ of $\mathrm{WGA}^{+} \mathrm{TG}$ neurons were $\mathrm{TRPV}^{+}{ }^{+}$(S3 and $\mathrm{S} 4$ groups) and all of these neurons were labeled with CGRP (Figs. 5B, B', 8C, 13C). Consistent with our electrophysiology data, TRPV $1^{+} / \mathrm{CGRP}^{-} \mathrm{TG}$ neurons, which have strong TRPV1 labeling (Fig. 5B, B', brown arrows), did not contain WGA.

Small-sized non-peptidergic (i.e., IB4 ${ }^{+} / \mathrm{CGRP}^{-}$) DRG neurons express MrgprD as a marker (Reynders et al., 2015; Patil et al., 2018). However, despite $24 \pm 2.4 \%$ of WGA $^{+}$cultured TG neurons staining for IB-4 (S1 and S2 groups), only a few $(3.1 \pm 0.7 \%, \mathrm{n}=3) \mathrm{MM} \mathrm{TG}$ neurons expressed MrgprD (Figs. $6 A, A^{\prime}, 8 C$ ). Anti-mrgprD antibodies are weak and generate high background (Fig. 6A, $A^{\prime}$ ); therefore, we used an alternative approach to confirm these data by back-tracing WGA from MM in MrgprD-creER/tdTomato reporter mice. Analysis of these sections confirmed that the MrgprD-cre ${ }^{+}$signal was only detected in a few TG MM neurons $\left(2.3 \pm 0.6 \%, n=3\right.$; Fig. $\left.6 B, B^{\prime}\right)$. However, some of MrgprD-cre ${ }^{+}$signals were registered in weakly labeled WGA ${ }^{+}$neurons (Fig. $6 B, B^{\prime}$ ). These data indicate that MrgprD may not be an appropriate marker for non-peptidergic MM TG neurons.

Single-cell transcriptomic of L3-L5 mouse DRG neurons assigned calbindin D28-positive $\left(\mathrm{Calb}^{+}\right)$neurons to group NF2 (Usoskin et al., 2015) or A $\beta$-Field (Sharma et 

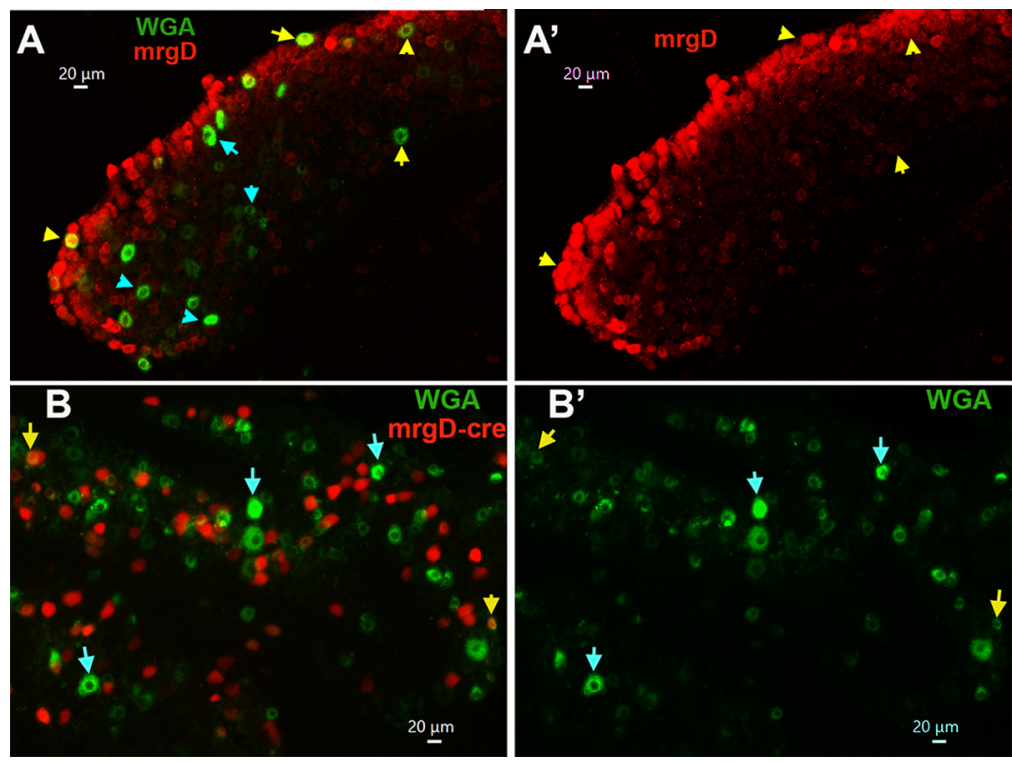

Figure 6. Expression of MrgprD in MM TG neurons. A, $\boldsymbol{A}^{\prime}$, Expression of MrgprD (mrgD; red) neurons in a TG section containing MM TG neurons (WGA; green). Objective is $20 \times . \boldsymbol{B}, \boldsymbol{B}^{\prime}$, Expression of MrgprD-cre/tdTomato (mrgD-cre; red) neurons in a TG section from mice back-traced from MM with WGA-488 (WGA; green). Objective is $20 \times$. MM TG neurons containing both mrgD or mrgDcre and WGA are marked with yellow arrows. MM TG neurons containing WGA, but not mrgD or mrgD-cre or trpV1, are marked with cyan arrows. White horizontal bar shows $20-\mu \mathrm{m}$ scale for each panel.

al., 2020). Functional studies on L3-L5 DRG Calb ${ }^{+}$neurons demonstrated that they are a subset of $A \beta$-LTMR neurons (Arcourt et al., 2017). TG MM neurons express Calb at low levels $\left(\approx 2 \%\right.$; Figs. $\left.7 A, A^{\prime}, 8 C\right)$. Recording from MM TG neurons isolated from PV-cre/tdTomato reporter mice showed that PV could be present in M2-M4 groups. IHC data indicate that PV antibodies had low signal in $\approx 21 \%$ MM TG neurons (Figs. 7B, B', 8C). Similarly, electrophysiology data on MM TG neurons from trkC/ tdTomato mice indicated that trkC could be found in groups S5, M2-M4. TrkC antibodies labeled $\approx 30 \%$ $\mathrm{WGA}^{+} \mathrm{TG}$ neurons (Fig. $\left.8 A, A^{\prime}, C\right)$. This implies that $\mathrm{S} 5$ are $\sim 5 \%$ of MM TG neurons (Fig. $13 C$ ). Our patch-clamp recordings did not show the presence of C-LTMR-like
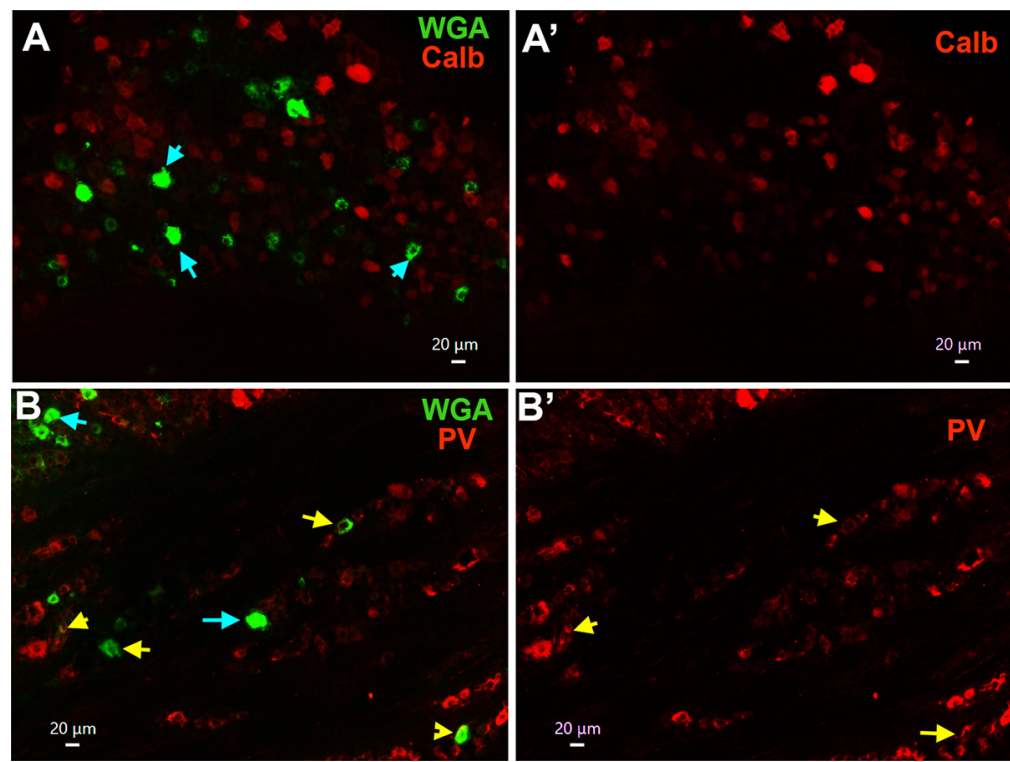

Figure 7. Expression of calbindin-D28 and parvalbumin mechanoreceptor markers in MM TG neurons. $\boldsymbol{A}, \boldsymbol{A}^{\mathbf{\prime}}$, Expression of calbindin D28 (Calb; red) in a TG section containing MM TG neurons (WGA; green). B, B', Expression of parvalbumin (PV; red) in a TG section containing MM TG neurons (WGA; green). MM TG neurons lacking Calb or PV are shown with cyan arrows. MM TG neurons containing Calb or PV are shown with yellow arrows. For all panels, objective is $20 \times$. White horizontal bar shows $20-\mu \mathrm{m}$ scale for each panel. 

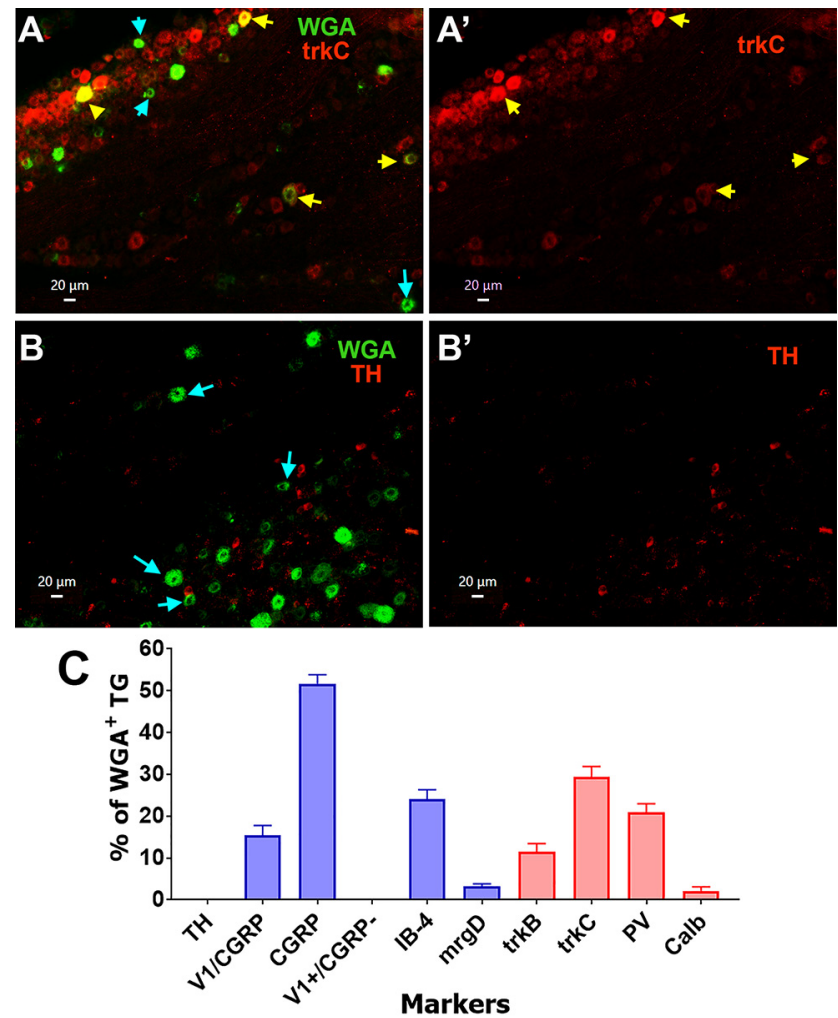

Figure 8. Expression of trkC and $\mathrm{TH}$ mechanoreceptor markers in MM TG neurons. $\boldsymbol{A}, \boldsymbol{A}^{\prime}$, Expression of trkC (trkC; red) in a TG section containing MM TG neurons (WGA; green). $\boldsymbol{B}, \boldsymbol{B}^{\prime}$, Expression of TH (red) in a TG section containing MM TG neurons (WGA; green). MM TG neurons lacking a sensory neuronal marker are shown with cyan arrows on the $\boldsymbol{A}, \boldsymbol{B}$ panels. MM TG neurons containing a sensory neuronal marker are shown with yellow arrows on the $\boldsymbol{A}, \boldsymbol{A}^{\prime}$ panels. For all panels, objective is $20 \times$. White horizontal bar shows $20-\mu \mathrm{m}$ scale for each panel. C, Percentages of $\mathrm{WGA}^{+} \mathrm{TG}$ neurons labeled with a variety of indicated sensory neuronal markers. Cell counting is from four animals, three to five sections each.

afferents among MM TG neurons. IHC confirmed that $\mathrm{TH}^{+}$(a marker for C-LTMR neurons) was not present among $\mathrm{WGA}^{+}$neurons (Fig. 8B, $B^{\prime}, C$ ). We did not detect any characteristic properties that would point to $A \delta$ LTMR-like (i.e., trkB ${ }^{+}$in DRG) afferents among patchclamp recorded neurons. However, trkB was found to be expressed in $11.5 \pm 1.9 \%$ of MM TG neurons (Fig. $8 C$ ). In conclusion, considering the information on expression percentages of $\mathrm{WGA}^{+} / \mathrm{CGRP}^{+}, \mathrm{WGA}^{+} / \mathrm{IB}^{-} 4^{+}$, and $\mathrm{WGA}^{+} /$ trkC $^{+}$as well as frequency of recordings from particular $\mathrm{MM}$ TG neuronal groups, we could estimate that $24 \%$ of MM TG neurons belong to groups S1 and S2; $15 \%$ to S3 and S2; $5 \%$ to $\mathrm{S} 5,24 \%$ to $\mathrm{M} 1 ; 5 \%$ to $\mathrm{M} 2 ; 12 \%$ to $\mathrm{M} 3$; and $10 \%$ to M4 (Fig. 13C).

\section{TG sensory afferent nerve types innervating masseteric muscle fibers and tendons}

The masseteric nerve enters the deep portion of $\mathrm{MM}$ and is divided into many branches within MM (Fig. 13A,B). These branches eventually supply the sensory afferent nerves that innervate MM fibers, tendon, muscle-tendon junction, and masseteric fascia. Injection into MM could lead to contamination and/or diffusion of WGA into subcutaneous tissue (Fig. 13B). Additionally, such an injection could label sensory afferent fibers in the main trunk of masseteric nerve (Fig. 13A,B). Using IHC, we examined the distribution of different sensory fiber types within MM, as well as innervation of muscle fibers, tendon, muscletendon junctions, and fascia surrounding whole MM.

The main trunk of the masseteric nerve brunches out from the mandibular nerve and enter the MM in the sigmoid fascia area (Kim et al., 2010; Fig. 13A,B). We found this area of masseteric nerve trunk contained $\mathrm{CGRP}^{+}$/ $\mathrm{NFH}^{-}$(yellow arrows; S3-S5 groups), $\mathrm{CGRP}^{+} / \mathrm{NFH}^{+}$(M1 and $\mathrm{M} 2$ groups; Fig. 9A, $A^{\prime}$, cyan arrows) and $\mathrm{CGRP}^{-} /$ $\mathrm{NFH}^{+}$(M3 and M4 groups; Fig. 9A, $A^{\prime}$, white arrows) sensory nerves. The masseteric nerve trunk then descends into MM between the middle and deep parts of muscle fibers and then divides into many nerve branches in the posterosuperior, posteroinferior, anterosuperior, and anteroinferior directions (Luo et al., 1991; Kim et al., 2010; Fig. $13 A, B)$. We observed that multiple branches of $\mathrm{CGRP}^{+}$and $\mathrm{NFH}^{+}$nerve bundles reached the deep and middle layers of the muscle and junctions of muscle fibers and tendon (Fig. 9B). Distribution of $\mathrm{CGRP}^{+}$and $\mathrm{NFH}^{+}$ nerve bundles and individual fibers occurred throughout MM. However, they mainly concentrate in tendon and at junctions between superficial, middle, and deep parts of MM (Fig. 9B,C,C'). Additionally, these fibers were found to innervate masseteric fascia, which surrounds the whole MM (Fig. 9D).

Analysis of multiple slides showed that $\mathrm{MM}$ tendons almost exclusively contained $\mathrm{CGRP}^{+} / \mathrm{NFH}^{+}(\mathrm{M} 1$ and $\mathrm{M} 2$ groups; Fig. $10 A, A^{\prime}$, cyan arrows) and $\mathrm{CGRP}^{-} / \mathrm{NFH}^{+}$ nerves (M3 and M4 groups; Fig. 10A,A', white arrows). Masseteric muscle fibers were also nearly exclusively innervated by $\mathrm{CGRP}^{+} / \mathrm{NFH}^{+}$(cyan arrows) or $\mathrm{CGRP}^{-} / \mathrm{NFH}^{+}$ (white arrow) MM TG neurons (Fig. 10B, $B^{\prime}$ ). This innervation pattern was detected around masseteric fascia as well (Fig. 9D). Thus, only 1-3 peptidergic $\mathrm{CGRP}^{+} / \mathrm{NFH}^{-}$ nerves (S3, S4, and maybe S5 groups) were observed in muscle fibers, adjacent tendons of MM and masseteric fascia investigated by $20 \times$ objective across $16-24 \mathrm{MM}$ sections generated from three to four mice.

To further investigate this unexpected finding, we examined $\mathrm{MM}$ distribution of nerves with peptidergic $\mathrm{CGRP}^{+}$/ $\mathrm{NFH}^{-}$markers such as trpV1 ${ }^{+}$, Nav1. $8^{+}$, and pgp9.5 $5^{+}$; and $\mathrm{NFH}^{-}$markers such as trkC ${ }^{+}$and $\mathrm{PV}^{+}$. Moreover, to evaluate whether these findings are translated across species, MM fiber types were labeled in the marmoset tissue. Pgp9.5 is marker for all types of sensory nerves, and could highlight location of non-peptidergic unmyelinated nerve fibers (Tokushige et al., 2006). Analysis 8-16 slides with MM sections from male mice showed that pgp9. $5^{+}$nerves innervating muscle fibers (Fig. 11A, $A^{\prime}$ ), tendon of MM (Fig. 11B), and masseteric fascia (Fig. 11C) are always co-labeled by NFH (cyan arrows on all panels). Muscle fibers of male marmosets were predominantly innervated by pgp9.5 $5^{+} / \mathrm{NFH}^{+}$ nerves (Fig. $11 D, D^{\prime}$, cyan arrows). However, pgp9.5 $5^{+} \mathrm{NFH}^{-}$ nerves (Fig. 11D, $D^{\prime}$, white arrows), which likely represent 

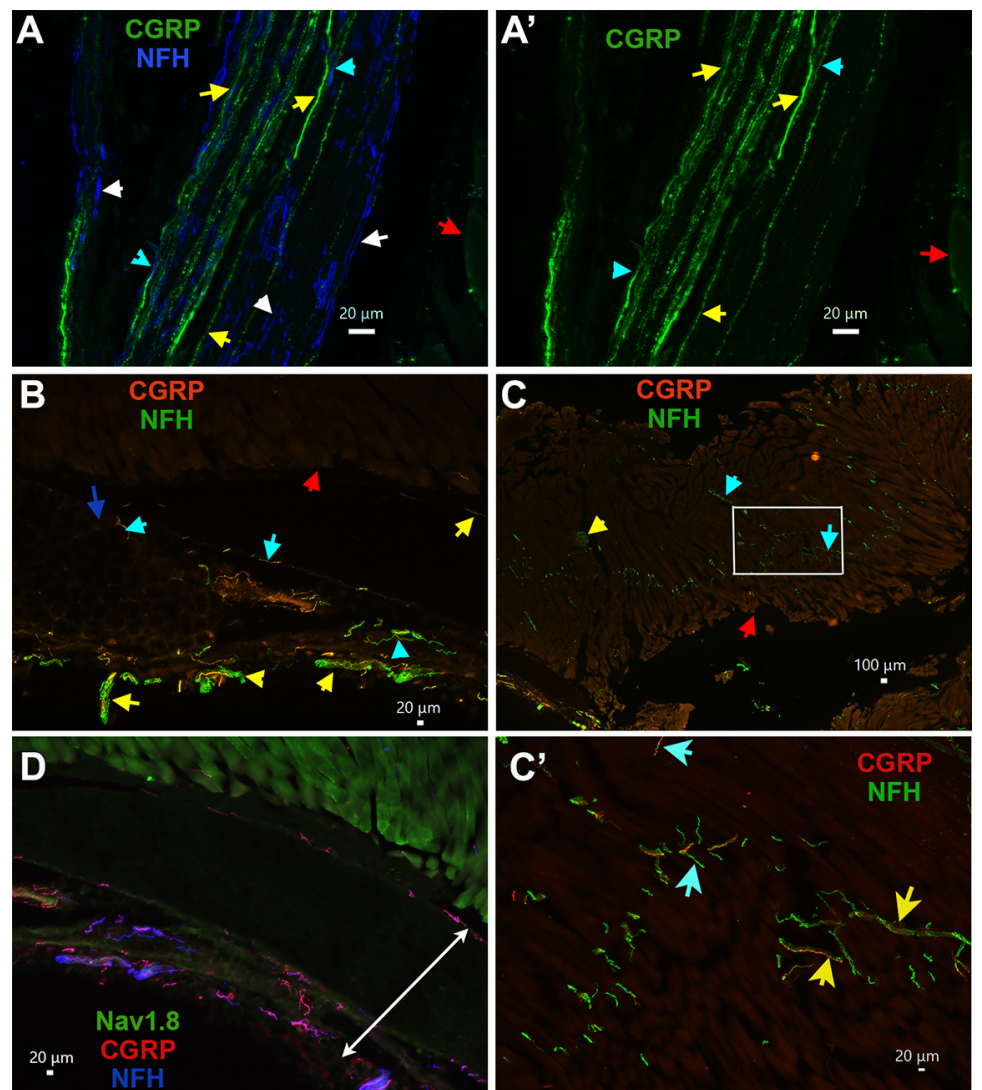

Figure 9. Location of $\mathrm{CGRP}^{+}$and $\mathrm{NFH}^{+}$TG sensory neuronal afferent fibers in MM. $\boldsymbol{A}, \boldsymbol{A}^{\prime}$, Expression of CGRP (green) and NFH (blue) fibers in a main trunk of the masseteric nerve located near MM. Objective is $40 \times . \mathrm{CGRP}^{+} / \mathrm{NFH}^{-}$nerves are marked with yellow, $\mathrm{CGRP}^{+} / \mathrm{NFH}^{+}$with cyan, and $\mathrm{CGRP}^{-} / \mathrm{NFH}^{+}$with white arrows. Red arrow shows MM fibers. B, Expression of CGRP (red) and $\mathrm{NFH}$ (green) nerves in muscle fibers and MM tendon. Objective is $10 \times$. Red arrow shows muscle fibers and blue points on tendons. Nerve bundles are marked with yellow arrows and individual nerves with cyan arrows. $\boldsymbol{C}$, Expression of CGRP (red) and NFH (green) nerves in MM. Objective is $2 \times$. A red arrow shows muscle fibers. C', High magnification (objective is $20 \times$ ) of the image within a white rectangle on the panel $\boldsymbol{C}$. On the panels $\mathbf{C}, \boldsymbol{C}^{\prime}$, nerve bundle is marked with a yellow arrow and individual nerves with cyan arrows. $\boldsymbol{D}$, Expression of Nav1.8-Ai32-YFP (green), CGRP (red), and NFH (blue) nerves in MM fascia area, which is indicated by white double arrowed line. Objective is $10 \times$. White horizontal bar shows $20-$ or $100-\mu \mathrm{m}$ scale for each panel.

C-fibers, were seldomly detected on one of two MM sections observed with $10 \times$ objective. These findings imply that male mouse MM fibers, tendon and fascia are almost solely innervated by A-fiber myelinated fibers, while C-fiber unmyelinated fibers are rarely encountered in MM fibers of marmosets.

TRPV1 marks S3 and S4 groups of MM TG neurons containing peptidergic unmyelinated fibers. TRPV $1^{+}$ nerves were not detected within masseteric muscle fibers (Fig. 11A, $A^{\prime}$ ), tendon or fascia of MM (data not shown). However, some nerve branches of masseteric nerve located along muscle fibers contain TRPV $1^{+}$sensory fibers, which was also labeled by pgp $9.5^{+}$(Fig. 11B, $B^{\prime}$, cyan arrows). Nav1. $8^{+}$fibers were highlighted by isolation of MM from Nav1.8-cre/Ai32-YFP mice. Electrophysiology recording showed that strong Nav1.8-YFP signal is detectable only in small neurons (S1-S4 groups), while M1 has weak Nav1.8 presence and S5 and M2-M4 have none. Hence, Nav1. $8^{+}$sensory fibers were not detected within muscle fibers and tendon. However, certain masseteric nerve branches contained Nav1. $8^{+}$fibers (Fig. 11C,C', red arrow). Interestingly, we have detected multiple nerve branches adjusted or inside MM expressing both pgp9.5 and NFH, but not showing Nav1.8 (Fig. 11C,C', yellow arrows). Expression patterns of $\mathrm{CGRP}^{+}$, pgp9. $5^{+}, \mathrm{Nav} 1.8^{+}$, and $\mathrm{NFH}^{+}$nerves within MM indicate that muscle fibers, tendon and fascia are innervated by M1-M4 and maybe S5 TG MM neurons. In concordance with this, trkC, which is a marker for S5 and M2-M4 MM TG neurons (Fig. 13C), was detected in many $\mathrm{NFH}^{+}$fibers (Fig. 11D,D', cyan arrows). However, unlike trkC, anti-PV antibodies produced only weak labeling in masseteric nerve branches (data not shown). Overall, our data suggest that muscle fibers, tendon, and fascia of MM in mice and marmosets are almost exclusively innervated by S5 and M1-M4 nerves, which are mainly distributed in tendon and at junctions of superficial, middle, and deep parts of MM. Unmyelinated IB- $4^{+}$, Nav1 $18^{+}$, and TRPV $1^{+}$nerves (S1-S4 neurons) are in a subset of masseteric nerve branches, but do not terminate in muscle fibers, tendon, and fascia of mice MM (Fig. $13 A, B)$. Additionally, it could not be excluded that WGA injected in MM could defuse into adjusted structures such as skin and especially, subcutaneous tissues, which contain unmyelinated C-fibers (see Discussion). 

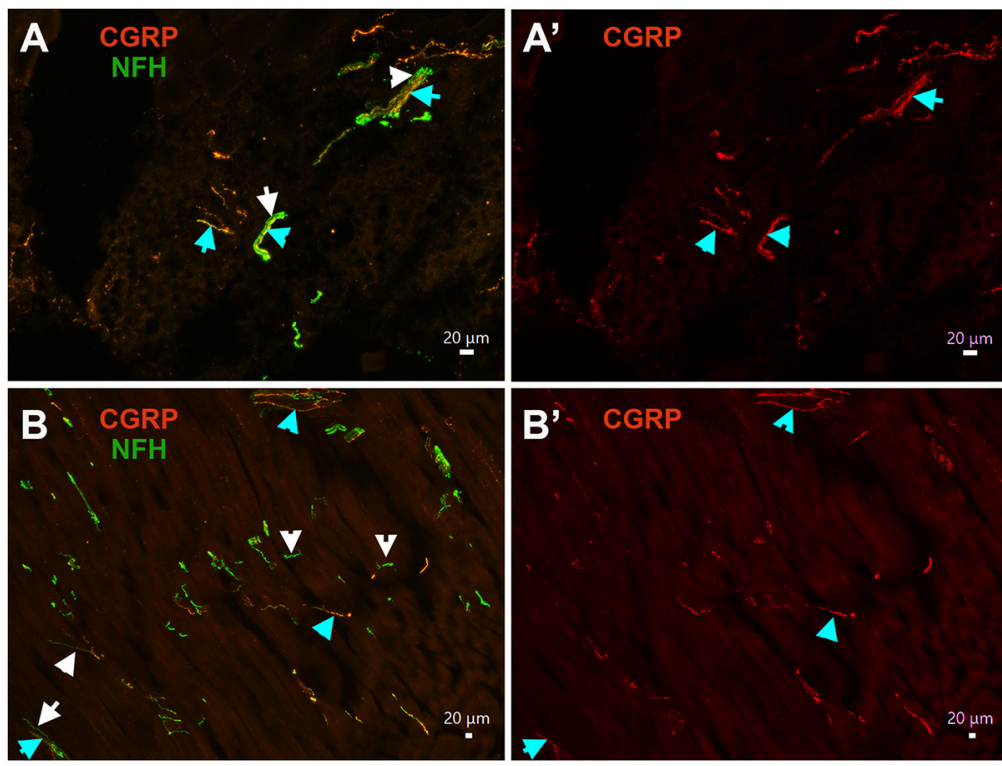

Figure 10. MM TG neuron types innervating mouse MM fibers and tendons. $\boldsymbol{A}, \boldsymbol{A}^{\prime}$, Expression of CGRP (red) and NFH (green) nerves in MM tendon. Objective is $20 \times . \mathrm{CGRP}^{+} / \mathrm{NFH}^{+}$nerves are marked with cyan and $\mathrm{CGRP}^{-} / \mathrm{NFH}^{+}$with white arrows. $\boldsymbol{B}, \boldsymbol{B}^{\prime}$, Expression of CGRP (red) and NFH (green) nerves in masseteric muscle fibers. Objective is $10 \times . \mathrm{CGRP}^{+} / \mathrm{NFH}^{+}$nerves are marked with cyan and $\mathrm{CGRP}^{-} / \mathrm{NFH}^{+}$with white arrows.

\section{Discussion}

Mechanisms underlying masticatory myofascial pain are largely unknown. Masticatory myofascial pain involves MM in several conditions, including TMD and after some restorative surgeries in the head and neck. In this respect, understanding jaw muscle and particularly MM innervation is critical for dissecting cell-specific mechanisms controlling development of chronic masticatory myofascial pain. This understanding will eventually allow for the effective management of TMD pain (Dinsdale et al., 2021). In addition, masseteric nerve is affected during certain restorative surgeries and during transplantations/transfers, which are the most often performed cranial nerve manipulation technique used to treat patients with facial paralysis (Corcoran and Goldman, 2021). In this study, using backtracking from MM with WGA, reporter mice driven by promoters of well-characterized sensory neuronal markers, patch clamp electrophysiology and IHC, we identified and characterized types of TG sensory neurons innervating $\mathrm{MM}$. This approach was successfully employed to identify and characterize neuronal groups in L3-L5 DRG and TG (Petruska et al., 2000; Xu et al., 2010; Patil et al., 2018). We clustered most recorded MM TG neurons into nine clusters (Fig. 13C; Table 2). One to two percent of recorded neurons did not fit these nine clusters. For example, MM TG neurons did not respond to ATP (Table 1), but from $>350$ analyzed neurons, seven responded to ATP.

There is not clear consensus on how the sensory neurons between DRG and TG differ. There is also not enough data on the biochemical differences between sensory neurons innervating the MM. Nevertheless, there is agreement that somatosensory neurons in different sensory ganglia have distinct anatomic, functional, physiological, and pathophysiological characteristics (Li, 2007;
Belmonte and Viana, 2008; Gambeta et al., 2020). Thus, DRG are located in the intervertebral foramina at spinal levels that mainly innervate tissues within the trunk, legs and feet, while TG rest in Meckel's cave and innervate the head and neck area (Vermeiren et al., 2020). Another anatomic distinction is proprioceptors with $\mathrm{A} \alpha$-fibers are located in DRG but are outside TG in the mesencephalic TG nucleus (Jerge, 1963; Dubner, 1986). Since physiological function of tissues in the trunk, legs and feet are quite distinct from tissues in head and neck area, it is presumed that DRG and TG sensory neurons have distinct, specialized, and unique sets of proteins/mRNA. With the advent of RNA-seq, data from sorted sensory neurons and single-cells described some of these differences in recent years (Usoskin et al., 2015; Lopes et al., 2017; Nguyen et al., 2019; Zheng et al., 2019; Mecklenburg et al., 2020; Renthal et al., 2020). However, these sequencing data indicate that the differences between sensory neurons in DRG and TG are not dramatic and lack clear functional distinctions (Lopes et al., 2017; Mecklenburg et al., 2020; Sharma et al., 2020). These differences between DRG and TG neurons could be because of analysis of sensory neuronal profiles in whole ganglia, but not in specific subsets of sensory neurons innervating defined tissues (such as muscle, skin, tooth, dura, etc.). Considering that neuronal subsets may have distinct origins and may therefore be guided to different targets, innervating different tissues (Hockley et al., 2019), we focused our study on a specific subset of TG neurons innervating MM.

Ideally, our data need to be compared with DRG neurons innervating hind/fore limb muscle. However, this information is not available. Single-cell data generated by several independent studies imply that difference between neuronal groups innervating limb skin and muscle 

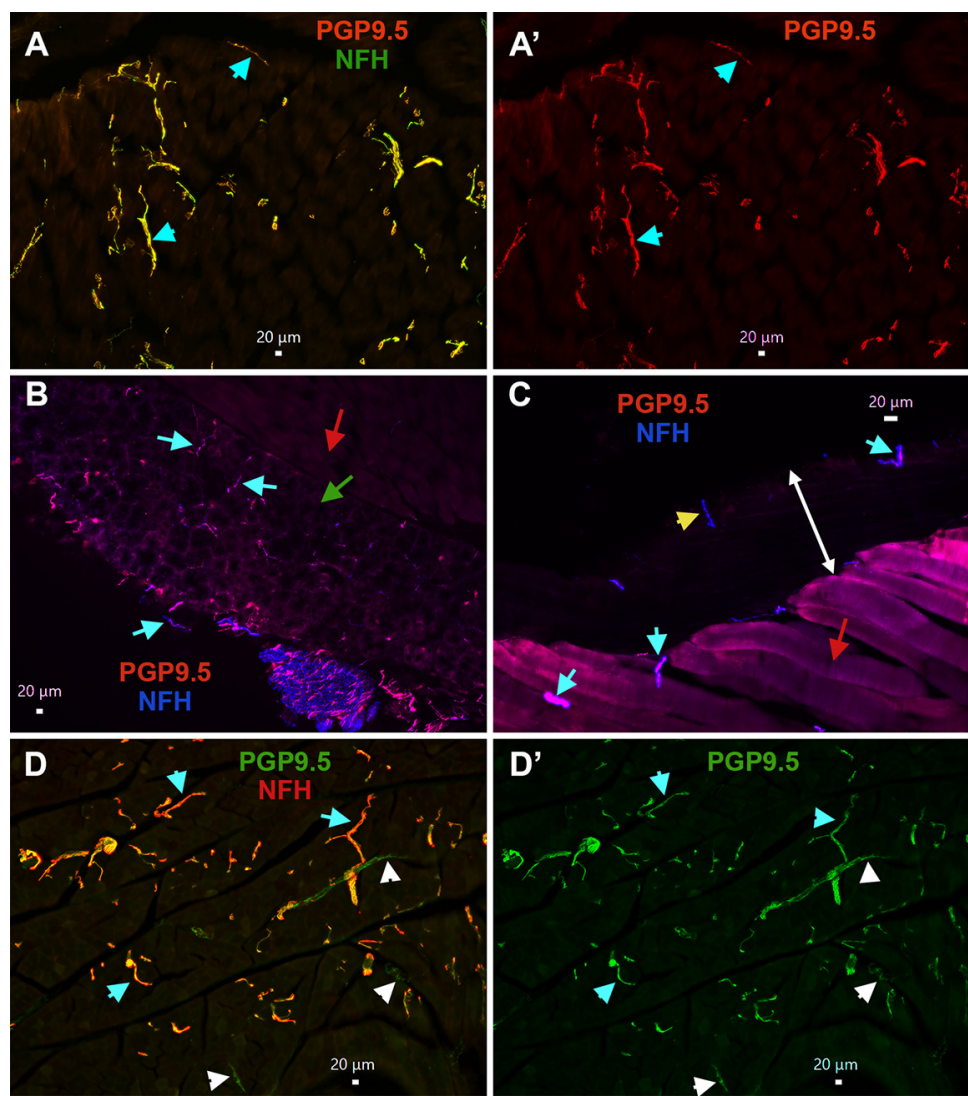

Figure 11. MM TG neuron types innervating MM in mice and common marmosets. $\boldsymbol{A}, \boldsymbol{A}^{\prime}$, Expression of pgp9.5 (red) and NFH (green) in male mouse masseteric muscle fibers. Objective is $10 \times$. Pgp $9.5^{+} / \mathrm{NFH}^{+}$nerves are shown with cyan arrows. $\boldsymbol{B}$, Expression of pgp9.5 (red) and NFH (blue) in male mouse MM tendon. Objective is $10 \times$. Muscle fibers are shown by a red arrow, and tendons by a green arrow. Pgp9.5 $/ \mathrm{NFH}^{+}$nerves are shown with cyan arrows. $\mathbf{C}$, Expression of pgp9.5 (red) and NFH (blue) in male mouse masseteric fascia. Objective is $20 \times$. Muscle fibers are shown by a red arrow, and fascia layer by a double-headed white arrow. Pgp9.5 ${ }^{+} / \mathrm{NFH}^{+}$nerves are shown with cyan arrows, and a Pgp9.5 $/ \mathrm{NFH}^{+}$nerve with a yellow arrow. $\boldsymbol{D}, \boldsymbol{D}^{\prime}$, Expression of pgp9.5 (green) and NFH (red) in 11-year-old male marmoset masseteric muscle fibers. Objective is $10 \times . \mathrm{Pgp}^{2} .5^{+} / \mathrm{NFH}^{+}$nerves are shown with cyan arrows, and Pgp9.5 ${ }^{+} / \mathrm{NFH}^{-}$nerves with white arrows. White horizontal bar shows $20-\mu \mathrm{m}$ scale for each panel.

maybe not substantial (Usoskin et al., 2015; Sharma et al., 2020). Thus, our data indicate that $20-25 \%$ of L3-L5 DRG neurons were labeled by WGA injected into limb muscles (Mecklenburg et al., 2020). Single-cell sequencing of thousands of sensory neurons clustered major phenotypic differences of DRG groups innervating the skin and muscle, for example, proprioceptors were clustered as a separate group (Usoskin et al., 2015; Sharma et al., 2020). Taken all these points into consideration, we compared our results with published data from whole L3-L5 DRG. S1 and S2 groups, which are Nav1.8 $8^{+}$, but not CGRP ${ }^{+}$, are classic CAP-unresponsive IB- $4^{+}$non-peptidergic sensory neurons (Stucky and Lewin, 1999). Unlike L3-L5 DRG neurons (Lou et al., 2015), MM TG IB-4 $4^{+}$neurons were not $\mathrm{MrgprD}^{+}$. Functional studies on DRG neurons distinguished two types of skin innervating $\mid \mathrm{B}-4^{+} /$ $\mathrm{MrgprD}^{+}$neurons: C-polymodal nociceptors $(\mathrm{PMN})$ and C-mechano-nociceptors (C-MN; Liu et al., 2012; Lou et al., 2015). For MM TG neurons, it is not clear what functions could be assigned to S1 and TRPA1 containing S2 groups. S3 and S4 groups containing CGRP, TRPV1 and Nav1.8 are likely C-PMN-like with similarities to DRG neurons (Usoskin et al., 2015; Patil et al., 2018; Sharma et al., 2020). The last small-sized MM TG neuronal group characterized was S5. It had unique electrophysiological properties (Table 1) and we observed expression of CGRP and trkC, but not Nav1.8 in S5 group MM TG neurons. There is no analog for S5 neurons in L3-L5 DRG; and it is unknown whether S5 express NFH and belong to nociceptors or LTMR. Unlike DRG neurons innervating skin, MrgprA3 ${ }^{+}$(C-PMN; Han et al., 2013), CGRP ${ }^{-}$/ $\mathrm{TRPV}^{+}{ }^{+}$(also known as somatostatin ${ }^{+}$; Usoskin et al., 2015), and $\mathrm{TH}^{+}$(also known as C-LTMR; Seal et al., 2009) groups were not found among MM TG neurons.

As it was previously reported (Sato et al., 2018), medium-sized neurons are most abundant among MM TG neurons (Fig. 13C). Moreover, in L3-L5 DRG innervating either skin or muscle, all CGRP ${ }^{+}$neurons were found inside of the Nav1.8 $8^{+}$subset (Patil et al., 2018), while S5, M1, and M2 MM TG neuronal groups expressed CGRP but little-to-no Nav1.8 (Fig. 13C). M1 and M2 mediumsized MM TG peptidergic neurons produced large inward currents on application of $5 \mathrm{HT}$. This property distinguished M1 and M2 from other MM TG neurons. M1 

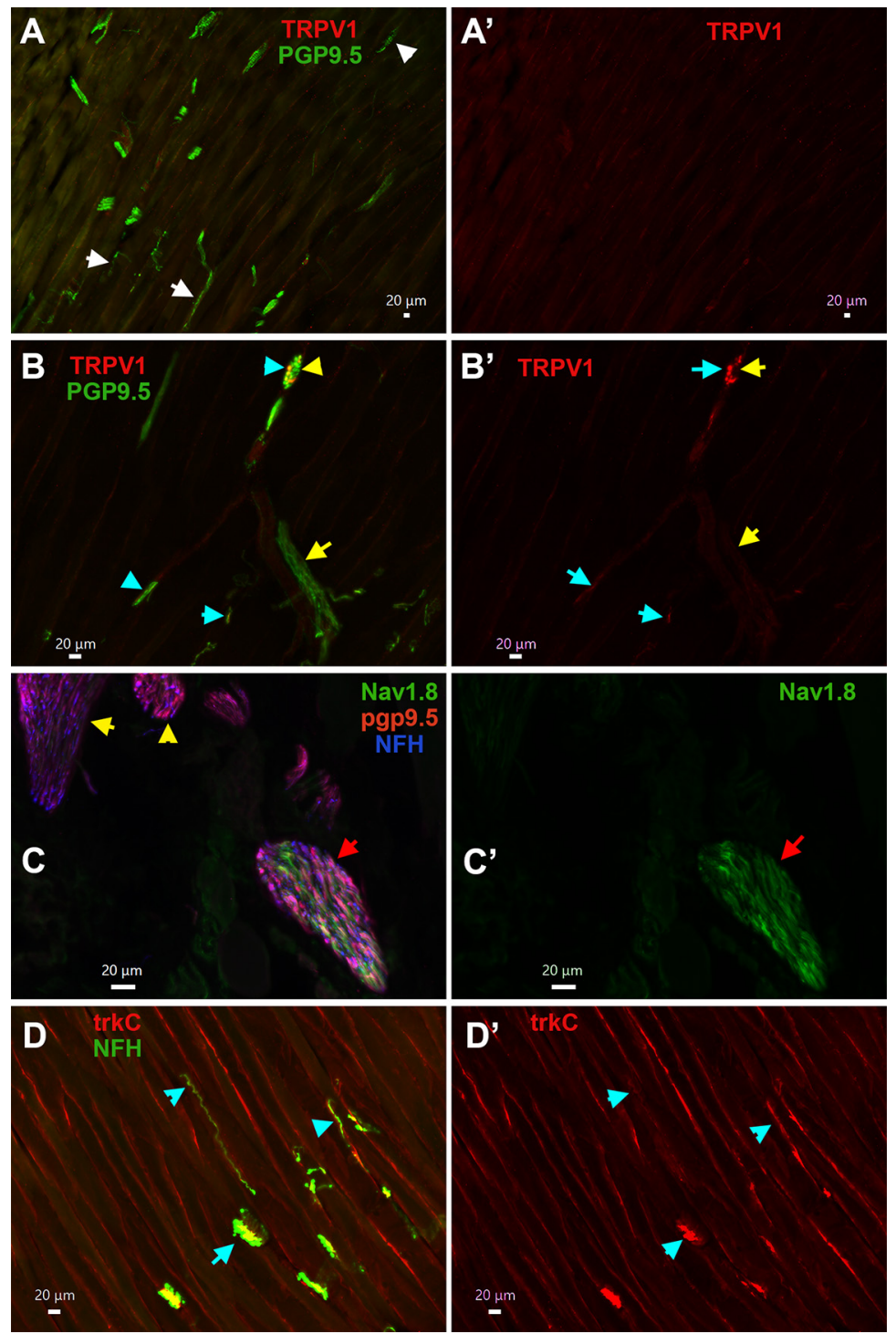

Figure 12. Expression of trpV1 $1^{+}, \mathrm{Nav} 1.8^{+}$, and trkC ${ }^{+}$sensory neuronal afferent fibers in MM. $\boldsymbol{A}, \boldsymbol{A}^{\prime}$, Expression of pgp9.5 (green) and TRPV1 (red) nerves in masseteric muscle fibers. Objective is $10 \times$. TRPV1 ${ }^{-} / \mathrm{pgp} 9.5^{+}$nerves are marked with white arrows. $\boldsymbol{B}, \boldsymbol{B}^{\prime}$, Expression of pgp9.5 (green) and TRPV1 (red) nerves in nerve bundles located within masseteric muscle fibers. Objective is $20 \times$. $\mathrm{TRPV}^{+} /$pgp9. $5^{+}$nerves are marked with cyan arrows. Yellow arrows show nerve bundles. C, C', Expression of Nav1.8-Ai32 (green), pgp9.5 (red), and NFH (blue) fibers in masseteric nerve branches. Objective is $40 \times$. A red arrow shows a branch with Nav1.8-Ai32 ${ }^{+}$fibers, and yellow arrows mark Nav1.8-Ai32 $2^{+}$branches. $\boldsymbol{D}, \boldsymbol{D}^{\prime}$, Expression of trkC (red) in $\mathrm{NFH}^{+}$(green) nerves within masseteric muscle fibers. Objective is $20 \times$. $\mathrm{TrkC}^{+} / \mathrm{NFH}^{+}$nerves are marked with cyan arrows. White horizontal bar shows $20-\mu \mathrm{m}$ scale for each panel.

contains CGRP, a no-to-low level of Nav1.8, and no trkC. Considering previous research on DRG (Usoskin et al., 2015; Patil et al., 2018), M1 could be a peptidergic myelinated A-fiber nociceptor (A $\delta$-HTMR). However, it is unclear whether previously described A-fiber nociceptors are distinct in limb skin versus muscle (Usoskin et al., 2015; Sharma et al., 2020). L3-L5 DRG contains two types of A $\delta$-HTMR, which express CGRP, Nav1.8, but not trkC, can be distinguished by the presence of NPY2R marker (Patil et al., 2018; Sharma et al., 2020). In contrast, TG MM M2 neurons have CGRP, trkC, and a no-to-low level of Nav1.8. Additionally, NPY2R-tdTomato expression have not been detected in TG neurons (Wu et al., 2018).
Such expression patterns in M2 MM TG neurons complicates their functional assignment. However, the presence of two A-fiber HTMR groups innervating MM has been reported (Wong et al., 2014); therefore, M2 could be a separate group of A-fiber HTMR, which are sometimes designated as $A \beta$-HTMR (Djouhri et al., 1998). MM is innervated by two TG neuronal groups, $\mathrm{M} 3$ and $\mathrm{M} 4$, that are not revealed in CGRP $\mathrm{Cre}^{\mathrm{ER} /+}$ and Nav1.8 ${ }^{\mathrm{cre} /+}$ reporter mice. However, M3 and M4 have been recorded among

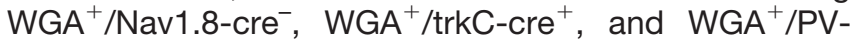
$\mathrm{cre}^{+}$TG neurons. In L3-L5 DRG innervating limb skin and muscle, functional studies suggested that $\operatorname{trkC}^{+} / \mathrm{PV}^{+}$are either skin $\mathrm{A} \beta$-LTMRs or muscle proprioceptors (Bai et 


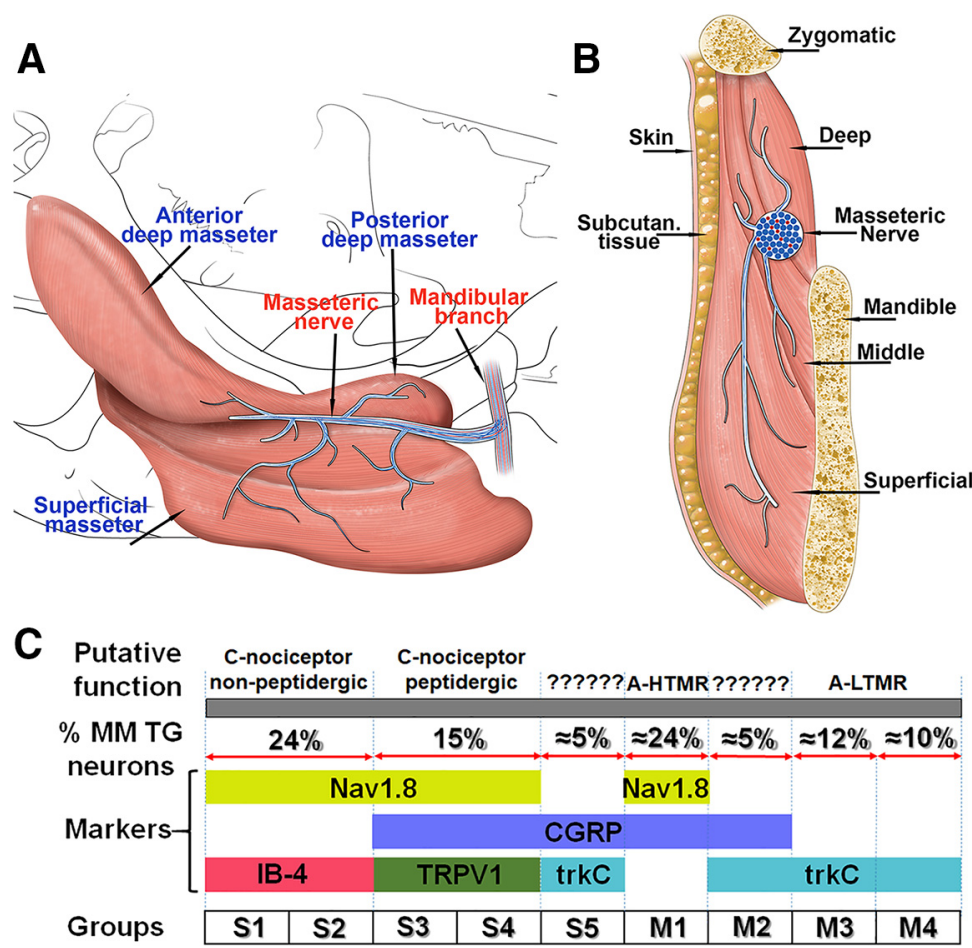

Figure 13. Schematic abstract of results. $\boldsymbol{A}$, Schematic of different parts of masseteric muscle (labeled) and branches of masseteric nerve (labeled). $\boldsymbol{B}$, Schematic of coronal section of MM with adjusted tissues. These adjacent tissues and MM components are labeled. On the panels $\boldsymbol{A}, \boldsymbol{B}$, blue lines and dots mark A-fibers, and red lines and dots represent $\mathrm{C}$-fibers in mandibular and masseteric nerves and in their branches. $\boldsymbol{C}$, Schematic TG neuronal groups (S1-S5, M1-M4) innervating MM. Expressions of neuronal markers are specified. Percentage of $\mathrm{WGA}^{+}$for each neuronal group based on IHC is shown. Putative functions of MM TG neuronal groups are suggested. A-HTMR are medium-sized A-nociceptors or high threshold mechanoreceptors. A-LTMR are medium-tolarge-sized A-low threshold mechanoreceptors. Putative functions of S5 and M2 are ambiguous, do not map onto previously described classes of DRG neurons, and marked as "unknown."

al., 2015). Since, TG do not have proprioceptors (Jerge, 1963), it could be presumed that M3 and M4 may be MM TG $A \beta$-LTMRs neurons. Subgroup of skin $A \beta$-LTMRs, called A $\beta$-Field, express calbindin D28 (Calb) as a marker (Arcourt et al., 2017; Sharma et al., 2020). Since Calb is not in MM TG neurons, it could be speculated that M3 and M4 are likely rapidly adapting A $\beta$-LTMRs (A $\beta$-RALTMRs). Interestingly, electrophysiological properties of M3 is similar to DRG skin innervating A $\beta$-RA-LTMRs nerves, but M4 strongly resembles DRG muscle innervating proprioceptors (Patil et al., 2018). Thus, their AP, a unique fast AHP, unresponsiveness to algesics and their outward I parameters are almost identical (Fig. 4B,D; Table 1) versus DRG group M7 (Patil et al., 2018). Skin hairs are innervated by C-LTMR or/and A $\delta$-LTMR DRG neurons, which express $\mathrm{TH}$ and trkB markers, respectively (Seal et al., 2009; Rutlin et al., 2015; Usoskin et al., 2015). Amongst MM TG neurons these neuronal groups have not been recorded.

Distribution of nerves in masseteric muscles has been studied in rats, rabbits, pig and cats (Gottlieb et al., 1984; Herring et al., 1989; Luo et al., 1991; Peker et al., 2001). It was shown that the masseteric nerve is subdivided into at least three to five subbranches within MM (Fig. 13A,B). Myelin sheets surrounding the unmyelinated nerve fibers disappeared as the fibers terminate (Herring et al., 1989).
Our data shows that unmyelinated and myelinated fibers travel together in a main trunk of the masseteric nerve (Fig. 9A, $A^{\prime}$ ). Similarly, nerve branches of the masseteric nerve contain either both unmyelinated and myelinated fibers or only myelinated fibers (Fig. $12 C, C^{\prime}$ ). It was reported that distribution of different types of fibers occur throughout MM and are independent of fiber type (Herring et al., 1989). First, the data indicate that afferent fibers are concentrated in tendons and at junctions between deep, middle, and superficial parts of MM (Fig. 9B,C,C'). Second, importantly, male mouse muscle fibers, tendons, and masseteric fascia of MM were almost exclusively innervated by myelinated $\mathrm{NFH}^{+}$afferent nerves (Figs. 9B,C, $\left.C^{\prime}, D, 10,11 A-C\right)$. Likewise, male marmoset MM were predominantly innervated by myelinated $\mathrm{NFH}^{+}$afferent nerves (Fig. 9D, $\left.D^{\prime}\right)$. Mouse MM TG neurons with myelinated fibers belong to M1-M4 groups, and maybe group S5 as well. IHC could detect unmyelinated MM TG neurons, which could be identified as $\mathrm{Nav} 1.8^{+} / \mathrm{NFH}^{-}$, TRPV $1^{+}$, and/or pgp9. $5^{+} / \mathrm{NFH}^{-}$afferent nerves, only within a subset of masseteric nerve branches (Fig. 12A-D'). It is not clear where these unmyelinated fibers terminate, since they were not detected by IHC in MM fibers, MM tendons and masseteric fascia. Accordingly, WGA injection into MM could label small TG neurons (S1-S4) found in the main trunk or sub-branches of the masseteric 
nerve, and/or adjacent to MM subcutaneous tissues and skin via WGA diffusion (Fig. 13A,B).

In conclusion, our data show that MM is almost exclusively innervated by myelinated nerves that can be divided into S5, M1-M4 neuronal groups (Fig. 13A-C). WGA injections into $\mathrm{MM}$ also revealed small sized TG neurons (S1-S4), nerve fibers from which are within the masseteric nerve or terminate in adjusted to MM structures (Fig. 13B, $C)$. Properties of these MM TG neuronal groups have similarities and many distinctions from the well-described and characterized L3-L5 DRG neurons innervating limb skin and muscles (Petruska et al., 2000; Usoskin et al., 2015; Patil et al., 2018; Sharma et al., 2020). These differences could imply distinct functional consequences during naive and pathologic conditions affecting MM. It also suggests that TG MM neurons may contain a discrete subset of receptors and channels, which could uniquely regulate sensitization of MM TG neurons during masticatory myofascial pain. Finally, our novel report on the innervation of $\mathrm{MM}$ in a non-human primate species, the common marmoset, is important for many reasons. Because of the close relatedness of nonhuman primates and humans, delineation of the MM in the marmoset is important to support its use as a potential animal model MM-related pathology. Further, identification of similarities between marmoset and mouse MM further supports the use of both species as preclinical models for development of intervention approaches in this area.

\section{References}

Arcourt A, Gorham L, Dhandapani R, Prato V, Taberner FJ, Wende H, Gangadharan V, Birchmeier C, Heppenstall PA, Lechner SG (2017) Touch receptor-derived sensory information alleviates acute pain signaling and fine-tunes nociceptive reflex coordination. Neuron 93:179-193.

Bai L, Lehnert BP, Liu J, Neubarth NL, Dickendesher TL, Nwe PH, Cassidy C, Woodbury CJ, Ginty DD (2015) Genetic identification of an expansive mechanoreceptor sensitive to skin stroking. Cell 163:1783-1795.

Belmonte C, Viana F (2008) Molecular and cellular limits to somatosensory specificity. Mol Pain 4:14.

Belugin S, Diogenes AR, Patil MJ, Ginsburg E, Henry MA, Akopian AN (2013) Mechanisms of transient signaling via short and long prolactin receptor isoforms in female and male sensory neurons. $J$ Biol Chem 288:34943-34955.

Chang W, Kanda H, Ikeda R, Ling J, DeBerry JJ, Gu JG (2016) Merkel disc is a serotonergic synapse in the epidermis for transmitting tactile signals in mammals. Proc Natl Acad Sci USA 113: E5491-E5500.

Cimmino MA, Ferrone C, Cutolo M (2011) Epidemiology of chronic musculoskeletal pain. Best Pract Res Clin Rheumatol 25:173-183.

Connor M, Naves LA, McCleskey EW (2005) Contrasting phenotypes of putative proprioceptive and nociceptive trigeminal neurons innervating jaw muscle in rat. Mol Pain 1:31.

Corcoran NM, Goldman EM (2021) Anatomy, head and neck, masseter muscle. In: StatPearls. Treasure Island: StatPearls Publishing.

Cruccu G, Agostino R, Inghilleri M, Manfredi M, Ongerboer de Visser BW (1989) The masseter inhibitory reflex is evoked by innocuous stimuli and mediated by A beta afferent fibres. Exp Brain Res 77:447-450.

da Silva Serra I, Husson Z, Bartlett JD, Smith ES (2016) Characterization of cutaneous and articular sensory neurons. Mol Pain 12:174480691663638.
Desai MJ, Saini V, Saini S (2013) Myofascial pain syndrome: a treatment review. Pain Ther 2:21-36.

Dinsdale A, Liang Z, Thomas L, Treleaven J (2021) Is jaw muscle activity impaired in adults with persistent temporomandibular disorders? A systematic review and meta-analysis. J Oral Rehabil 48:487-516.

Djouhri L, Bleazard L, Lawson SN (1998) Association of somatic action potential shape with sensory receptive properties in guineapig dorsal root ganglion neurones. J Physiol 513:857-872.

Dubner R (1986) Pain control in dentistry: the anatomic and physiologic basis of orofacial pain. Compend Contin Educ Dent 7:408,410406,418.

Dunkley PR, Bobrovskaya L, Graham ME, von Nagy-Felsobuki El, Dickson PW (2004) Tyrosine hydroxylase phosphorylation: regulation and consequences. J Neurochem 91:1025-1043.

Fang X, Djouhri L, McMullan S, Berry C, Waxman SG, Okuse K, Lawson SN (2006) Intense isolectin-B4 binding in rat dorsal root ganglion neurons distinguishes $\mathrm{C}$-fiber nociceptors with broad action potentials and high Nav1.9 expression. J Neurosci 26:72817292.

Galasso A, Urits I, An D, Nguyen D, Borchart M, Yazdi C, Manchikanti L, Kaye RJ, Kaye AD, Mancuso KF, Viswanath O (2020) A Comprehensive review of the treatment and management of myofascial pain syndrome. Curr Pain Headache Rep 24:43.

Gambeta E, Chichorro JG, Zamponi GW (2020) Trigeminal neuralgia: an overview from pathophysiology to pharmacological treatments. Mol Pain 16:1744806920901890.

Gerwin RD (2001) Classification, epidemiology, and natural history of myofascial pain syndrome. Curr Pain Headache Rep 5:412-420.

Gottlieb S, Taylor A, Bosley MA (1984) The distribution of afferent neurones in the mesencephalic nucleus of the fifth nerve in the cat. J Comp Neurol 228:273-283.

Han L, Ma C, Liu Q, Weng HJ, Cui Y, Tang Z, Kim Y, Nie H, Qu L, Patel KN, Li Z, McNeil B, He S, Guan Y, Xiao B, Lamotte RH, Dong $X$ (2013) A subpopulation of nociceptors specifically linked to itch. Nat Neurosci 16:174-182.

Herring SW, Wineski LE, Anapol FC (1989) Neural organization of the masseter muscle in the pig. J Comp Neurol 280:563-576.

Herrity AN, Rau KK, Petruska JC, Stirling DP, Hubscher CH (2014) Identification of bladder and colon afferents in the nodose ganglia of male rats. J Comp Neurol 522:3667-3682.

Hockley JRF, Taylor TS, Callejo G, Wilbrey AL, Gutteridge A, Bach K, Winchester WJ, Bulmer DC, McMurray G, Smith ESJ (2019) Single-cell RNAseq reveals seven classes of colonic sensory neuron. Gut 68:633-644.

Jerge CR (1963) Organization and function of the trigeminal mensencephalic nucleus. J Neurophysiol 26:379-392.

Kim DH, Hong HS, Won SY, Kim HJ, Hu KS, Choi JH, Kim HJ (2010) Intramuscular nerve distribution of the masseter muscle as a basis for botulinum toxin injection. J Craniofac Surg 21:588-591.

Lassus P, Lindford A, Vuola J, Bäck L, Suominen S, Mesimäki K, Wilkman T, Ylä-Kotola T, Tukiainen E, Kuokkanen H, Törnwall J (2018) The Helsinki Face Transplantation: surgical aspects and 1year outcome. J Plast Reconstr Aesthet Surg 71:132-139.

Li L, Rutlin M, Abraira VE, Cassidy C, Kus L, Gong S, Jankowski MP, Luo W, Heintz N, Koerber HR, Woodbury CJ, Ginty DD (2011) The functional organization of cutaneous low-threshold mechanosensory neurons. Cell 147:1615-1627.

$\mathrm{Li} \mathrm{Y}$ (2007) Sensory signal transduction in the vagal primary afferent neurons. Curr Med Chem 14:2554-2563.

Liu Q, Sikand P, Ma C, Tang Z, Han L, Li Z, Sun S, LaMotte RH, Dong $X$ (2012) Mechanisms of itch evoked by beta-alanine. J Neurosci 32:14532-14537.

Lobbezoo F, van der Glas HW, van der Bilt A, Buchner R, Bosman F (1996) Sensitivity of the jaw-jerk reflex in patients with myogenous temporomandibular disorder. Arch Oral Biol 41:553-563.

Lobbezoo F, Trulsson M, Jacobs R, Svensson P, Cadden SW, van Steenberghe D (2002) Topical review: modulation of trigeminal sensory input in humans: mechanisms and clinical implications. $J$ Orofac Pain 16:9-21. 
Lopes DM, Denk F, McMahon SB (2017) The molecular fingerprint of dorsal root and trigeminal ganglion neurons. Front Mol Neurosci 10:304.

Lorenzo LE, Godin AG, Wang F, St-Louis M, Carbonetto S, Wiseman PW, Ribeiro-da-Silva A, De Koninck Y (2014) Gephyrin clusters are absent from small diameter primary afferent terminals despite the presence of GABA(A) receptors. J Neurosci 34:8300-8317.

Lou S, Pan X, Huang T, Duan B, Yang FC, Yang J, Xiong M, Liu Y, $\mathrm{Ma} Q$ (2015) Incoherent feed-forward regulatory loops control segregation of C-mechanoreceptors, nociceptors, and pruriceptors. J Neurosci 35:5317-5329.

Luo PF, Wang BR, Peng ZZ, Li JS (1991) Morphological characteristics and terminating patterns of masseteric neurons of the mesencephalic trigeminal nucleus in the rat: an intracellular horseradish peroxidase labeling study. J Comp Neurol 303:286-299.

Ma FY, Grattan DR, Bobrovskaya L, Dunkley PR, Bunn SJ (2004) Angiotensin II regulates tyrosine hydroxylase activity and mRNA expression in rat mediobasal hypothalamic cultures: the role of specific protein kinases. J Neurochem 90:431-441.

Mecklenburg J, Zou Y, Wangzhou A, Garcia D, Lai Z, Tumanov AV, Dussor G, Price TJ, Akopian AN (2020) Transcriptomic sex differences in sensory neuronal populations of mice. Sci Rep 10:15278.

Neeb L, Hellen P, Boehnke C, Hoffmann J, Schuh-Hofer S, Dirnagl U, Reuter U (2011) IL-1 $\beta$ stimulates COX-2 dependent PGE(2) synthesis and CGRP release in rat trigeminal ganglia cells. PLoS One 6:e17360.

Nguyen MQ, Le Pichon CE, Ryba N (2019) Stereotyped transcriptomic transformation of somatosensory neurons in response to injury. Elife 8:e49679.

Ninkina N, Grashchuck M, Buchman VL, Davies AM (1997) TrkB variants with deletions in the leucine-rich motifs of the extracellular domain. J Biol Chem 272:13019-13025.

Nishimori T, Sera M, Suemune S, Yoshida A, Tsuru K, Tsuiki Y, Akisaka T, Okamoto T, Dateoka Y, Shigenaga Y (1986) The distribution of muscle primary afferents from the masseter nerve to the trigeminal sensory nuclei. Brain Res 372:375-381.

Patil MJ, Henry MA, Akopian AN (2014) Prolactin receptor in regulation of neuronal excitability and channels. Channels (Austin) 8:193-202.

Patil MJ, Hovhannisyan AH, Akopian AN (2018) Characteristics of sensory neuronal groups in CGRP-cre-ER reporter mice: comparison to Nav1.8-cre, TRPV1-cre and TRPV1-GFP mouse lines. PLoS One 13:e0198601.

Peker T, Turgut HB, Gülekon N, Anil A (2001) Demonstration of the nerve distribution of the masticatory muscles in rabbits (Oryctolagus cuniculus). Anat Histol Embryol 30:225-229.

Petruska JC, Napaporn J, Johnson RD, Gu JG, Cooper BY (2000) Subclassified acutely dissociated cells of rat DRG: histochemistry and patterns of capsaicin-, proton-, and ATP-activated currents. J Neurophysiol 84:2365-2379.

Procopio Pinheiro R, Gaubeur MA, Itezerote AM, Saleh SO, Hojaij F, Andrade M, Jacomo AL, Akamatsu FE (2020) Anatomical study of the innervation of the masseter muscle and its correlation with myofascial trigger points. J Pain Res 13:3217-3226.

Renthal W, Tochitsky I, Yang L, Cheng YC, Li E, Kawaguchi R, Geschwind DH, Woolf CJ (2020) Transcriptional reprogramming of distinct peripheral sensory neuron subtypes after axonal injury. Neuron 108:128-144.e9.

Resnikoff H, Metzger JM, Lopez M, Bondarenko V, Mejia A, Simmons HA, Emborg ME (2019) Colonic inflammation affects myenteric alpha-synuclein in nonhuman primates. J Inflamm Res 12:113-126.

Reynders A, Mantilleri A, Malapert P, Rialle S, Nidelet S, Laffray S, Beurrier C, Bourinet E, Moqrich A (2015) Transcriptional profiling of cutaneous MRGPRD free nerve endings and C-LTMRs. Cell Rep 10:1007-1019.

Robertson B (1990) Wheat germ agglutinin binding in rat primary sensory neurons: a histochemical study. Histochemistry 94:81-85.

Roy S, Sen CK, Ghatak S, Higuita-Castro N, Palakurti R, Nalluri N, Clark A, Stewart R, Gallego-Perez D, Prater DN, Khanna S (2020)
Neurogenic tissue nanotransfection in the management of cutaneous diabetic polyneuropathy. Nanomedicine 28:102220.

Ruparel NB, Patwardhan AM, Akopian AN, Hargreaves KM (2008) Homologous and heterologous desensitization of capsaicin and mustard oil responses utilize different cellular pathways in nociceptors. Pain 135:271-279.

Rutlin M, Ho CY, Abraira VE, Cassidy C, Bai L, Woodbury CJ, Ginty DD (2015) The cellular and molecular basis of direction selectivity of Adelta-LTMRs. Cell 160:1027.

Salas MM, Hargreaves KM, Akopian AN (2009) TRPA1-mediated responses in trigeminal sensory neurons: interaction between TRPA1 and TRPV1. Eur J Neurosci 29:1568-1578.

Sato M, Sato T, Yajima T, Shimazaki K, Ichikawa H (2018) The transient receptor potential cation channel subfamily $\mathrm{V}$ members 1 and 2, P2X purinoceptor 3 and calcitonin gene-related peptide in sensory neurons of the rat trigeminal ganglion, innervating the periosteum, masseter muscle and facial skin. Arch Oral Biol 96:6673.

Schurmans S, Schiffmann SN, Gurden H, Lemaire M, Lipp HP, Schwam V, Pochet R, Imperato A, Böhme GA, Parmentier M (1997) Impaired long-term potentiation induction in dentate gyrus of calretinin-deficient mice. Proc Natl Acad Sci USA 94:1041510420.

Schwaller B, Dick J, Dhoot G, Carroll S, Vrbova G, Nicotera P, Pette D, Wyss A, Bluethmann H, Hunziker W, Celio MR (1999) Prolonged contraction-relaxation cycle of fast-twitch muscles in parvalbumin knockout mice. Am J Physiol 276:C395-C403.

Seal RP, Wang X, Guan Y, Raja SN, Woodbury CJ, Basbaum Al, Edwards RH (2009) Injury-induced mechanical hypersensitivity requires C-low threshold mechanoreceptors. Nature 462:651-655.

Sharma N, Flaherty K, Lezgiyeva K, Wagner DE, Klein AM, Ginty DD (2020) The emergence of transcriptional identity in somatosensory neurons. Nature 577:392-398.

Slade GD, Ohrbach R, Greenspan JD, Fillingim RB, Bair E, Sanders AE, Dubner R, Diatchenko L, Meloto CB, Smith S, Maixner W (2016) Painful temporomandibular disorder: decade of discovery from OPPERA studies. J Dent Res 95:1084-1092.

Strassman AM, Raymond SA (1999) Electrophysiological evidence for tetrodotoxin-resistant sodium channels in slowly conducting dural sensory fibers. J Neurophysiol 81:413-424.

Strassman AM, Raymond SA, Burstein R (1996) Sensitization of meningeal sensory neurons and the origin of headaches. Nature 384:560-564.

Stucky CL, Lewin GR (1999) Isolectin B(4)-positive and -negative nociceptors are functionally distinct. J Neurosci 19:6497-6505.

Tokushige N, Markham R, Russell P, Fraser IS (2006) High density of small nerve fibres in the functional layer of the endometrium in women with endometriosis. Hum Reprod 21:782-787.

Usoskin D, Furlan A, Islam S, Abdo H, Lönnerberg P, Lou D, HjerlingLeffler J, Haeggstrom J, Kharchenko O, Kharchenko PV, Linnarsson S, Ernfors P (2015) Unbiased classification of sensory neuron types by large-scale single-cell RNA sequencing. Nat Neurosci 18:145-153.

Vermeiren S, Bellefroid EJ, Desiderio S (2020) Vertebrate sensory ganglia: common and divergent features of the transcriptional programs generating their functional specialization. Front Cell Dev Biol 8:587699.

Wieckiewicz M, Boening K, Wiland P, Shiau YY, Paradowska-Stolarz A (2015) Reported concepts for the treatment modalities and pain management of temporomandibular disorders. J Headache Pain 16:106.

Wong H, Dong XD, Cairns BE (2014) Nerve growth factor alters the sensitivity of rat masseter muscle mechanoreceptors to NMDA receptor activation. J Neurophysiol 112:2275-2282.

Wu P, Arris D, Grayson M, Hung CN, Ruparel S (2018) Characterization of sensory neuronal subtypes innervating mouse tongue. PLoS One 13:e0207069.

Xu S, Ono K, Inenaga K (2010) Electrophysiological and chemical properties in subclassified acutely dissociated cells of rat 
trigeminal ganglion by current signatures. J Neurophysiol 104:3451-3461.

Zappulo A, van den Bruck D, Ciolli Mattioli C, Franke V, Imami K, McShane E, Moreno-Estelles M, Calviello L, Filipchyk A, PegueroSanchez E, Müller T, Woehler A, Birchmeier C, Merino E, Rajewsky N, Ohler U, Mazzoni EO, Selbach M, Akalin A, Chekulaeva M (2017) RNA localization is a key determinant of neurite-enriched proteome. Nat Commun 8:583.
Zeisel $A$, Hochgerner $H$, Lönnerberg $P$, Johnsson $A$, Memic $F$, van der Zwan J, Häring M, Braun E, Borm LE, La Manno G, Codeluppi S, Furlan A, Lee K, Skene N, Harris KD, Hjerling-Leffler J, Arenas E, Ernfors P, Marklund U, Linnarsson S (2018) Molecular architecture of the mouse nervous system. Cell 174:999-1014 e1022.

Zheng Y, Liu P, Bai L, Trimmer JS, Bean BP, Ginty DD (2019) Deep sequencing of somatosensory neurons reveals molecular determinants of intrinsic physiological properties. Neuron 103:598-616.e7. 